\title{
Effects of of hypoxia on metabolic functions in marine organisms: Observed patterns and modelling assumptions within the context of Dynamic Energy Budget (DEB) theory
}

\author{
Thomas Yoann ${ }^{1,}{ }^{*}$, Flye Sainte Marie Jonathan ${ }^{5}$, Chabot Denis ${ }^{2}$, Aguirre-Velarde Arturo ${ }^{3,5}$, \\ Marques Gonçalo $\mathrm{M}^{4}$, Pecquerie Laure ${ }^{5}$
}

1 UBO, LEMAR, CNRS, Ifremer,IRD, Plouzane, France.

2 Fisheries \& Oceans Canada, Inst Maurice Lamontagne, Mont Joli, PQ, Canada.

3 IMARPE, Lab Ecofisiol Acuat, Esquina Gamarra \& Gen Valle S-N Chucuito, Callao, Peru.

4 Univ Lisbon, MARETEC, Inst Super Tecn, Av Rovisco Pais 1, P-1049001 Lisbon, Portugal.

*Corresponding author : Yoann Thomas, email address : yoann.thomas@ird.fr

\begin{abstract}
:
Hypoxia is a decrease in dissolved oxygen that causes physiological disturbances in marine fishes and invertebrates, including reduced mobility, growth rate and reproductive success, altered phenology and increased vulnerability to diseases. Under pressure from global changes such as warming or eutrophication, ocean and coastal ecosystems worldwide are becoming less oxygenated. In order to better understand the consequences of hypoxia on marine systems, there is a need for predicting hypoxiainduced changes from individual organisms to populations. By combining the effect of several stressors on species metabolic performances and life-history traits across their full life-cycle, the Dynamic Energy Budget (DEB) theory offers a suitable framework for studying the consequences of hypoxia on marine organisms and to envision an upscaling of these effects at population level through individual-based modelling approaches. Here, we propose a set of stylized biological facts which give a broad generalization of the effects of hypoxia on metabolic functions based on empirical findings. We used these stylized facts to derive assumptions on how to incorporate the effects of hypoxia on marine organisms in the framework of the DEB theory. We then validate some of these assumptions on marine species for which experimental datasets under hypoxic conditions and DEB parameters were available. We discuss the main issues that need to be dealt with, such as the various time-scales, ontogenic responses and multi-stressor effects which appear now as important targets of investigation for studying the effect of hypoxia on marine organisms.
\end{abstract}




\section{Highlights}

- Hypoxia has become a worldwide phenomenon in the coastal ocean. We proposed stylized biological facts about the effect of hypoxia on marine organisms. Based on these facts we established assumptions in the framework of the DEB theory. We validated some of these assumptions on three marine species. We discuss the main issues that need to be dealt with in future works. 


\section{Introduction: hypoxia in marine systems}

Hypoxia can be defined as a decrease in dissolved oxygen (DO) that forces fishes and aquatic invertebrates to either work harder at extracting oxygen from the water, or reduce their rate of energy expenditure to match the availability of oxygen. This phenomenon has become more frequent and intense worldwide in the coastal ocean and causes a deterioration of the structure (e.g. species assemblage, food-web structure) and function (e.g. biological or geochemical processes) of ecosystems (Zhang et al., 2010). Low oxygen waters are naturally formed in areas where vertical stratification prevents deeper water layers from getting replenished in oxygen, such as oxygen minimum zones (OMZs), deep basins, upwelling areas of eastern boundary currents, and deep water in fjords (Helly and Levin, 2004). Heterogeneity in water density, through freshwater input or surface water warming, and wind- or tide-induced mixing, are the main factors driving water stratification and are largely involved in producing water masses with low DO (Kemp et al., 2009). But 
during the last century, anthropogenic processes (e.g., nutrient loading) have caused large increases in the number of areas suffering from hypoxia and in the intensity or duration of hypoxia (Breitburg et al., 2018; Diaz and Rosenberg, 2008; Rabalais et al., 2010). Water masses can become under-saturated with oxygen when oxygen consumption (e.g. by organic pollution and enhanced bacterial respiration) exceeds oxygen production, dissolution from atmosphere or advection (Gray et al., 2002). Human-induced eutrophication of coastal waters is thus a major cause of hypoxia, through domestic sewage and agricultural fertilizers input, largely via rivers discharge (Grall and Chauvaud, 2002). Due to these human-induced processes, hypoxia tends to increase faster in the coastal ocean, compared to the open ocean (Gilbert et al., 2010). Diaz and Rosenberg (2008) and more recently Breitburg et al. (2018) reported that the number of human-caused coastal hypoxic areas increased from 195 in the 1990s to over 500 in recent years, affecting more than 250,000 square kilometres, and linked this increase with human activities in the watersheds.

Low DO conditions in different systems vary across a wide range of temporal scales. Following Kemp et al. (2009), four broad categories of hypoxia can be defined, depending on their duration: (1) permanent, (2) persistent seasonal, both stratified and vertically mixed, (3) episodic, and (4) diel. Permanent hypoxia is dominated by natural process and takes place in deep and stratified water (e.g., fjords, inland sea). Persistent seasonal hypoxia occurs in stratified temperate regions and shelf regions where spring river discharge and summer heat strengthen stratification and sustain primary production and subsequent organic matter degradation in the bottom layer. Episodic hypoxia is mainly driven by wind conditions and occurs at irregular intervals (weeks to decades) in productive, shallow (5$15 \mathrm{~m}$ ), weakly-stratified and microtidal coastal systems subjected to wind mixing. Diel hypoxia occurs in shallow lagoons and bays, driven by photosynthetic processes, which produce $\mathrm{O}_{2}$ during the day and consume $\mathrm{O}_{2}$ at night.

In the future, both anthropogenic factors and global changes are susceptible to interact on coastal eutrophication and associated hypoxia. Indeed, more coastal systems, especially in areas of increased human activities and where the physical conditions limit water renewal, will likely become eutrophic with accompanying hypoxia. Concurrently, a potential consequence of global warming is a decrease in oceanic DO due to (1) the reduction of $\mathrm{O}_{2}$ solubility in warmer water, (2) changes in ocean circulation (i.e., stratification) and (3) biological processes (i.e., thermally enhanced decomposition rate, respiration) (Keeling et al., 2009). Global changes may also cause synergistic effects between hypoxia and for example warming or hypercapnia (i.e., increase in $\mathrm{CO}_{2}$ partial pressure), which will increase 
species' sensitivity by acting on their tolerance ranges (Deutsch et al., 2015; Pörtner et al., 2005; Vaquer-Sunyer and Duarte, 2011; Verberk et al., 2016). Similarly, the presence of sulfide, which is produced from the anaerobic degradation of organic matter, decreases the ability of organisms to tolerate hypoxia (Vaquer-Sunyer and Duarte, 2010).

Oxygen is a key element for efficient energy production and animals, including fishes and aquatic invertebrates, meet most of their energy requirements through aerobic processes. Thus, oxygen consumption is a good approximation of metabolic rate (Nelson, 2016), including the cost of maintenance, digestion, growth and reproduction. Low DO may have a significant impact at the individual and population levels of both benthic and pelagic species (Wu, 2002a). Although the literature seems to converge toward a single threshold value to define hypoxia, close to $2 \mathrm{mg} \mathrm{O}_{2} \mathrm{~L}^{-1}$ (i.e., $1.4 \mathrm{~mL} \mathrm{O}_{2} \mathrm{~L}^{-1}, 63 \mu \mathrm{mol} \mathrm{O} \mathrm{L}^{-1}$ or approximately $30 \%$ saturation) (Rabalais et al., 2010), hypoxia tolerance and threshold are species- and stage-specific and may vary enormously (Ekau et al., 2010; Vaquer-Sunyer and Duarte, 2008). In a study by Vaquer-Sunyer and Duarte (2008), based on $>870$ published experiments on $>200$ species, a strong variation in lethal concentration was evidenced and ranged in average from $2.45 \mathrm{mg} \mathrm{O}_{2} \mathrm{~L}^{-1}$ for crustaceans to $0.89 \mathrm{mg} \mathrm{O}_{2} \mathrm{~L}^{-1}$ for gastropods. These differences across taxa probably reflect the adaptations to low oxygen conditions, which span a broad range of behavioural (i.e., capacity to avoid hypoxic waters) and metabolic changes (e.g., inherently low metabolic rate, ability to increase oxygen extraction from water, ability to shift to anaerobic metabolism).

At the individual level, sublethal hypoxia causes physiological disturbances which can alter many aspects of life history, including phenology, growth rates, reproductive success, increased vulnerability to diseases and parasites (Long et al., 2013a) and disturbances of locomotor activity (Domenici et al., 2007). At the population and ecosystem level, hypoxia will cause loss of suitable habitat for bottom-dwelling species and habitat compression for pelagic fishes, altered migration, loss of biomass and species richness and trophic mismatch, which will displace energy flow toward microbial pathways to the detriment of higher trophic levels (Diaz and Rosenberg, 2008; Rabalais et al., 2010). Depending on hydrographical conditions, ecosystem functioning could also be negatively affected in much larger areas adjacent to hypoxic ecosystems (Lichtschlag et al., 2015).

A large body of work has experimentally evaluated the combined effect of multiple environmental factors (i.e., temperature, salinity, oxygen, $\mathrm{CO}_{2}$ ) on the metabolic and growth rate to define species tolerance range and evaluate the consequences of environmental heterogeneity at individual and population levels (Brandt et al., 2009). Results have been primarily used to develop tools to compute species' aerobic scope (AS), the difference 
between the maximal $\mathrm{O}_{2}$ consumption and the standard or resting metabolic rate, SMR, (Claireaux and Lagardère, 1999; Haure et al., 2003; Schurmann and Steffensen, 1997), or model growth, reproduction and survival (Miller Neilan and Rose, 2014). Most of these modelling approaches remain largely empirical, despite some of them developing a bioenergetics approach by taking into account the effect of temperature and body size (Hartman and Brandt, 1995). While these kinds of metabolic indices are useful to investigate the potential consequences of variable $\mathrm{O}_{2}$ supply on species' physiology and subsequent biogeography (Deutsch et al., 2015), they do not incorporate sub-individual mechanisms (i.e. metabolic fluxes such as e.g. assimilation, reserve mobilization) linking physiological responses and energy balance to environmental variables such as hypoxia at individual level. Moreover, they usually do not take into account the species life cycle and are mostly species-specific.

The Dynamic Energy Budget (DEB) theory offers a quantitative (i.e. mass and energy) framework to model metabolic fluxes at the individual level. These fluxes modulate substrate uptake and use: energy assimilation toward a reserve buffer, reserve mobilization, allocation to growth, development, reproduction and maintenance and sustain life-history traits dynamics: growth rate, life-stage transitions, reproductive output and mortality (Kooijman, 2010). The DEB model follows the individual through its complete life cycle, from the embryo to juvenile and adult stages. DEB theory is well suited for modelling the effect of multi-stressors on metabolism, including e.g. food, temperature, osmosis or chemical compounds (Kooijman, 2017). Due to its mechanistic approach, DEB theory makes it possible to deal with ontogenic processes (Zimmer et al., 2014) and to address processes at various scales, from sub-individual to individual and to upper level of organization (population to ecosystem) (Martin et al., 2013; Sousa et al., 2010). Note that all reasoning and discussion applies to all typified DEB models and specifically to the standard DEB model or models with acceleration (Kooijman, 2014). For simplicity purposes from here on we will refer to the standard DEB model. The standard DEB model assumes that food availability is the only limiting substrate. Even if oxygen uptake and use are properly formalized in the standard DEB model through elemental compounds (i.e. C, $\mathrm{H}, \mathrm{N}$ and $\mathrm{O}$ ) dynamics (see supplementary materials for details), oxygen is not considered as a limiting substrate in the standard model. But it is reasonable to assume oxygen limitation impacts multiple physiological pathways and aspects of the energetic budget, from energy acquisition to allocation for growth and/or reproduction and dissipation for maintenance costs. 
Here, we discuss how empirical evidence of sub-lethal physiological responses to hypoxia, measured at the individual scale in marine organisms, might be summarized into simple rules in the framework of DEB theory, giving a broad generalization of the effects of hypoxia on metabolic functions based on empirical findings. Second, these rules are used to formulate assumptions regarding the effects of hypoxia on physiological functions within the DEB framework. These assumptions are then explored for their validity on several species. Finally, coupled experimental and modelling approaches are suggested for future research.

\section{Physiological responses to hypoxia}

Animals may show different patterns of oxygen consumption in response to changes in ambient oxygen partial pressure $\left(\mathrm{PO}_{2}\right)$ (Fry, 1971; Pörtner and Grieshaber, 1993). The concept of critical $\mathrm{PO}_{2}$, noted $\mathrm{PcO}_{2}$, characterizes the oxygen $\mathrm{PO}_{2}$ below which an organism is no longer able to maintain its minimum rate of oxygen consumption and exhibits a decreasing rate of oxygen uptake (i.e. below its standard metabolic rate, Claireaux and Chabot, 2016). $\mathrm{PcO}_{2}$ indicates the transition from oxygen independency to oxygen dependency, as well as characterizes the onset of anaerobic energy metabolism (Pörtner and Grieshaber, 1993). Nonetheless, it appears obvious that $\mathrm{PcO}_{2}$ varies with the environmental conditions e.g., with temperature (Artigaud et al., 2014) or salinity (Bayne, 1973), the physiological state of a given animal e.g., depending on respiratory pigment affinity with $\mathrm{O}_{2}$ (Spoek, 1974), or with body size (Bayne, 1971a; Herreid II, 1980). When confronted with severe hypoxia (lower than $\mathrm{PcO}_{2}$ ), species may develop anaerobic processes to sustain their energetic demand. Under these circumstances, reserves (e.g., carbohydrates) are metabolized anaerobically to produce energy (i.e., adenosine triphosphate, ATP) to maintain all or a part of the organism's total energetic expenditure, but with low ATP yield (15-fold less efficiency) and production of toxic metabolic byproducts. Alternatively, organisms have been shown to decrease metabolic rate in stressful environments (i.e. metabolic suppression, Hochachka, 1986), presumably to avoid the negative consequences of anaerobiosis and increase tolerance to low-oxygen conditions.

\subsection{Hypoxia and energy uptake}

A decrease in food consumption was recorded for numerous marine organisms submitted to hypoxia, such as fishes (Brandt et al., 2009; Chabot and Dutil, 1999; Pichavant et al., 2001), bivalves (Aguirre-Velarde et al., 2018; Baker and Mann, 1994; Le Moullac et 
al., 2007; Norkko et al., 2005; Sobral and Widdows, 1997), crustaceans (Desai and Prakash, 2009), echinoderms (Siikavuopio et al., 2007) and gastropods (Cheung et al., 2008a). Food intake may thus be one of the most important determinants of growth rate impairment under hypoxia. For example, reduction in food uptake explains $97 \%$ of the growth rate variance in Atlantic cod (Gadus morhua) experimentally submitted to hypoxia (Chabot and Dutil, 1999). This relationship between feeding rate and growth, which suggests that a reduction in feeding is a major cause of growth limitation under hypoxia, was evidenced for numerous other species, such as turbot (Scophthalamus maximus), grooved carpet shell (Ruditapes decussatus) or summer and winter flounders (Paralichthys dentatus and Pseudopleuronectes americanus) (Pichavant et al., 2000; Sobral and Widdows, 1997; Stierhoff et al., 2006).

A diversity of oxy-regulatory strategies describing the dependency of feeding rate on oxygen concentration have been recorded and appeared to be highly species-specific. Examples are given on Fig. 2-1 for Atlantic cod (Chabot and Dutil, 1999), striped bass, Morone saxatilis (Brandt et al., 2009), Pacific oyster (Le Moullac et al., 2007), green mussel, Perna viridis (Wang et al., 2011), sea urchin, Strongylocentrotus droebachiensis (Siikavuopio et al., 2007), grooved carpet shell, Ruditapes decussatus (Sobral and Widdows, 1997) and barnacle, Balanus Amphitrite (Desai and Prakash, 2009). Especially, the barnacle and grooved carpet shell maintain a consistently high level of feeding rate until a critical point of $20 \%$ DO saturation. Conversely, the Pacific oyster and Atlantic cod exhibit a higher sensitivity to the oxygen saturation with a continuous decrease of their feeding rate (cf. Fig 2-1). These patterns of sensitivity could be linked to the species' oxygen consumption regulation strategy. Indeed, a decrease in feeding rate may be viewed as an oxygen saving strategy, by the reduction in the rate of the non-essential and costly processes such as ingestion, digestion and absorption of food (i.e., specific dynamic action, SDA), which represent e.g. about $17 \%$ of the total energetic expenditure for the mussel Mytilus edulis (Widdows et al., 1989). Furthermore, several fish species need to spend a large fraction of their aerobic scope in the digestive process (Jordan and Steffensen, 2007). $A$ reduction in feeding rate thus reduces the energy demand and thereby decreases $\mathrm{O}_{2}$ requirements (Pichavant et al., 2000; Wu, 2002a). 


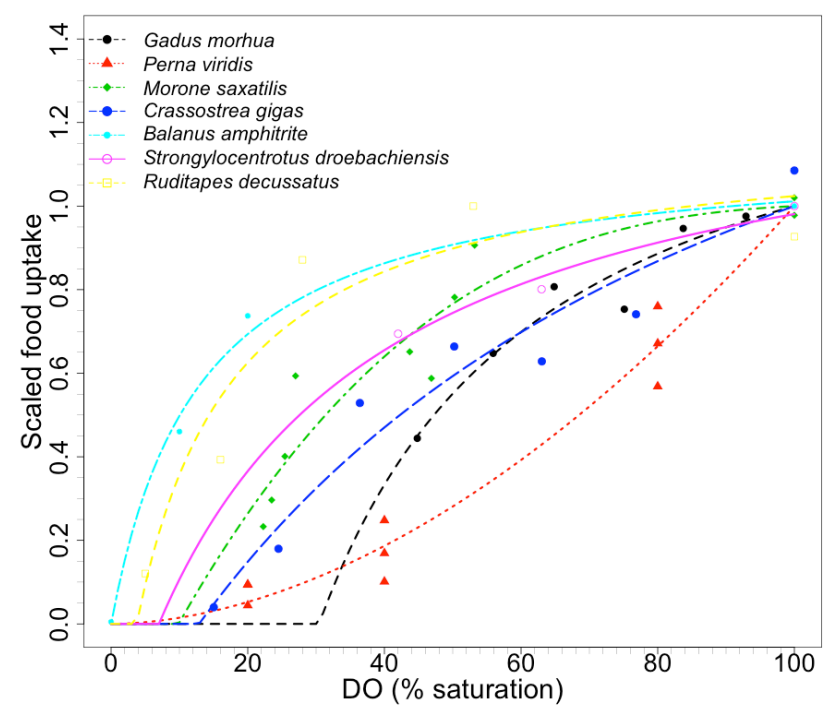

Fig 2-1 Ingestion rate at various levels of dissolved $\mathrm{O}_{2}$ for various species. References are given in the text. Data are scaled according to the result simulated at $\mathrm{O}_{2}$ sat. $=100 \%$.

Life-history stage is also considered an important determinant of the relative sensitivity of organisms to hypoxia. For example, several studies conducted on bivalves demonstrated the link between development stage and the effect of low oxygen level on feeding rate: sensitivity to hypoxia increased with increasing size in developing larvae, and conversely, decreased with increasing size in post-settlement (e.g., juvenile) for oyster and mussel (Baker and Mann, 1994; Wang and Widdows, 1991; Widdows et al., 1989).

The assimilation efficiency ( $A E$ ) is defined as the proportion of ingested energy entering into the reserves through assimilation, the remainder being evacuated with the faeces. Many studies have shown that AE is reduced by decreasing DO (e.g. green mussel: Wang et al., 2011; Chinese shrimp: Wei et al., 2009; common carp: Zhou et al., 2001), leading to less energy uptake under hypoxia. Conversely, AE may also be independent to external environment conditions in several species, as for the gastropod Nassarius festivus (Cheung et al., 2008a). In the case of the clam (Ruditapes decussatus), the assimilation efficiency is even enhanced by hypoxic conditions from $34.6 \%$ at $11 \mathrm{kPa}$ to $69.3 \%$ at $1.2 \mathrm{kPa}$ (Sobral and Widdows, 1997). The effect of hypoxic conditions on food assimilation efficiency seems thus to be very species-dependent.

\subsection{Hypoxia and growth}

Two hypotheses explain the decrease in growth when organisms are exposed to hypoxia: (1) a decrease in energy uptake; as previously highlighted, a reduction in food consumption seems to be the major cause of growth limitation, and (2) an increase of 
energy expenditure; for example, cost for ventilation or locomotion to avoid hypoxic waters may decrease the energy available for growth (Kramer, 1987). Some species would also be able to modify their energy allocation under hypoxic conditions, such as the gastropod Nassarius festivus, for which most of the energy acquired was allocated to either shell growth or reproduction, the energy allocated to body tissue growth being relatively insignificant (Cheung et al., 2008a). Similar changes in energy allocation were evidenced in the common carp (Cyprinus carpio) and Chinese shrimp (Fenneropenaeus chinensis) submitted to hypoxic conditions. Energy uptake was significantly reduced and energy allocation was mainly oriented toward respiration processes (Wei et al., 2009; Zhou et al., 2001).

\subsection{Hypoxia and reproduction}

Hypoxia clearly reduces reproductive output in numerous marine organisms, typically by reducing gonadal growth (i.e., decrease of the gonado-somatic index, GSI) (Zhou et al., 2001) possibly associated with the reduced aerobic scope (AS). For example, hypoxia (from $\mathrm{DO}=4 \mathrm{mg} \mathrm{O}_{2} \mathrm{~L}^{-1}$ to $2 \mathrm{mg} \mathrm{O}_{2} \mathrm{~L}^{-1}$ ) reduced egg production by $40 \%$ in Macoma balthica (Long et al., 2013a). Similarly, carp (Cyprinus carpio) GSI was reduced by $60 \%$ between 7 and 1 $\mathrm{mg} \mathrm{O}_{2} \mathrm{~L}^{-1}$ (Wu et al., 2003), by $75 \%$ between 5.6 and $1.7 \mathrm{mg} \mathrm{O}_{2} \mathrm{~L}^{-1}$ for the Atlantic croaker (Micropogonias undulatus) (Thomas et al., 2006), and by $30 \%$ between 9.5 and $4 \mathrm{mg} \mathrm{O}_{2} \mathrm{~L}^{-}$ ${ }^{1}$ for the sea urchin (Strongylocentrotus droebachiensis) (Siikavuopio et al., 2007). The reduction in gonad growth was correlated with the decrease in food uptake and thus the energy supply in sea urchin (Siikavuopio et al., 2007). However, the link between hypoxia and reproduction impairment is still poorly understood in most species.

Hypoxia can also impair reproduction by acting as a specific cue regulating gamete production and quality (Siikavuopio et al., 2007). Indeed, hypoxia is known to disrupt endocrine functions, which in turn affect gametogenesis, sexual maturity, gamete quality and fecundity (Wu et al., 2003). Thomas et al., (2006) demonstrated ovarian dysfunction in the Atlantic croaker (Micropogonias undulatus), leading to a decrease in the production of fully grown oocytes and a reduction in viable gametes. These dysfunctions were related to a significant decrease in endocrine indicators of the oestrogen-signalling pathway in the plasma, regulating the production of the yolk protein precursor sequestered by the growing oocytes (i.e., vitellogenin). This type of alteration of specific hormonal pathways mediating the production of gametes was also demonstrated for e.g. the Gulf killifish (Fundulus grandis) (Landry et al., 2007) or the common carp (Cyprinus carpio) (Wu et al., 2003). For the latter, hypoxia reduced overall reproductive success by disturbing endocrine functions 
(decrease of testosterone and increase of $17 \beta$-estradiol in male fish and decrease in $17 \beta-$ estradiol and triiodothyronine in female fish), which in turn reduced gametogenesis (i.e., inhibiting sperm production, stop oocyte maturation), sexual maturity (i.e., reduce GSI), gamete quality (i.e., reduce sperm motility and yolk in each egg), and subsequent fecundity, fertilization success, hatching, and viability of larvae (Wu et al., 2003).

\subsection{Hypoxia and dissipated energy}

The Dissipation flux in the DEB framework has a specific definition: it includes all the transformations with reserve and $\mathrm{O}_{2}$ as substrates and $\mathrm{CO}_{2}$, nitrogen waste and water as products (e.g. somatic maintenance, activity). The other two transformations are Assimilation (food $+\mathrm{O}_{2}$ transformed into reserve + metabolic products) and Growth (reserve $+\mathrm{O}_{2}$ transformed into structure + metabolic products). A decrease in $\mathrm{O}_{2}$ availability may thus reduce the metabolic energy production provoking a general metabolic depression. Some species of animals may thus enter into a hypometabolic state, their ATP turn over and demand can be down-regulated by more than an order of magnitude, and metabolic rate reduced e.g. by 5-20 fold during hypoxia, from 7 to $1 \mathrm{mgO}_{2} \mathrm{l}^{-1}$ (Wu et al., 2003). In that case, most of the energy derived from food is required for maintenance when food ingestion is very limited, even stopped, and the animal mostly lives on energy reserves: there is a reduced aerobic scope, so the cost for processing food (SDA) is not overcast. Moreover increased ventilation cost during digestion under low oxygenation levels could reduce conversion efficiency (Chabot and Claireaux, 2008).

Organisms may respond to hypoxia conditions by behavioural compensation, leading to escape from hypoxic water, or to a reduction of the activity and thus limiting energy and $\mathrm{O}_{2}$ consumption (Herreid II, 1980; Schurmann and Steffensen, 1997; Wei et al., 2009). These behaviours can change energy expenditure for activity in opposite ways and then act on dissipation rate accordingly: more energy expenditure with increased activity (e.g. escape) or less energy expenditure with reduced activity.

\subsection{Lethal oxygen level}

The reasons why organisms die in hypoxic conditions may be related (1) to the reduction in ATP production through oxidative phosphorylation, which leads to the cell depolarisation by impairment of ion pumping, initiating necrotic and apoptotic mechanisms, and (2) through acidosis caused by anaerobic metabolism (i.e., accumulation of lactate and $\mathrm{H}^{+}$endproducts) (Nilsson and Östlund-Nilsson, 2008). The averaged median lethal oxygen 
concentration $\left(L C_{50}\right)$ and median lethal time $\left(L T_{50}\right)$ summarized for 206 marine benthic organisms was found to be $2.05 \mathrm{mg} \mathrm{O}_{2} \mathrm{~L}^{-1}$ and $268 \mathrm{~h}$, with $90 \%$ of the experiments showing $\mathrm{LC}_{50}$ values below $4.59 \mathrm{mgO}_{2} \mathrm{~L}^{-1}$, with significant differences across taxa (Vaquer-Sunyer and Duarte, 2008).

Lethal oxygen concentration may vary with temperature and the interaction between warming and deoxygenation is perceived to be both strong and worrisome as both drivers are likely to co-occur in many coastal areas. As already mentioned in this section, the vast majority of marine organisms being ectotherms, ocean warming will increase their metabolic rate and, therefore, will increase their oxygen requirements. At the same time, oxygen solubility decreases as temperature increases (Garcia and Gordon, 1992), making it more difficult for these species to extract oxygen from the water to meet their enlarging oxygen requirements, even though this is partly offset by the increasing oxygen diffusivity coefficient in water and decreasing water viscosity as water temperature increases (Verberk et al., 2011). Interaction between hypoxia and temperature has been described for several species, such as for the spider crab (Maja brachydactyla), which shows a LC $\mathrm{C}_{50}$ varying from 6.8 to $19.3 \%$ sat., positively correlated with temperature (Valverde et al., 2012). For the Atlantic cod (Gadus morhua), Schurmann \& Steffensen (1997) measured a $\mathrm{PcO}_{2}$ at 16.5, 23.2 and $30.3 \%$ at 5,10 and $15^{\circ} \mathrm{C}$, respectively. The same trend was demonstrated for several freshwater fishes by Ott et al. (1980).

Hypoxia tolerance is also influenced by body mass scaling relationships. In their review, Nilsson \& Östlund-Nilsson (2008) reached two main conclusions on this topic: (1) in most cases, oxygen consumption and gill surface area show virtually identical body mass scaling relationship exponents, suggesting a match between gill surface area and the requirement for oxygen uptake, over a large body size range (see also Pauly \& Cheung (2018) and Lefevre et al. (2017) for more details), and that the ability to take up oxygen during hypoxia is independent of size. There are exceptions: hypoxia tolerance has been shown do increase with body size in some species (e.g. spider crab, Maja brachydactyla Valverde et al. 2012 and Greenland halibut Reinhardtius hippoglossoides, Dupont-Prinet et al., 2013b) and decrease with body size in others (northern shrimp Pandalus borealis, Dupont-Prinet et al., 2013a); (2) under severe hypoxia, below $\mathrm{PcO}_{2}$, where organisms have to rely on anaerobic ATP production (glycolysis) for survival, large individuals have a clear advantage over smaller ones, because small individuals will run out of glycogen or reach lethal levels of anaerobic end products (lactate and $\mathrm{H}^{+}$) much faster due to their higher mass-specific metabolic rate. These general conclusions imply that within species, body size typically has 
little impact on hypoxia tolerance, but large individuals may survive longer below the critical hypoxia level than small ones.

\subsection{Stylized biological facts for modelling assumptions}

Following the stylized empirical patterns essential for a theoretical description of metabolic organization in biology, summarized by Sousa et al. (2008), we synthesize here in simple rules: stylized biological facts, the observed metabolic responses of marine organisms submitted to hypoxia, in order to give modelling assumptions consistent with the Dynamic Energy Budget theory. These facts are related to the metabolic processes common to all the organisms: Feeding, growth, reproduction, respiration, and survival.

Table 1. Stylized biological facts giving a summary of the metabolic responses of marine organisms to hypoxia.

\begin{tabular}{|c|c|}
\hline & Stylized facts \\
\hline \multirow[t]{2}{*}{ Feeding } & $\begin{array}{l}\text { F1. Organisms reduce their feeding rate with decreasing } \\
\text { DO level. }\end{array}$ \\
\hline & $\begin{array}{l}\text { F2. Food assimilation efficiency can be enhanced [1], } \\
\text { unchanged [2] or reduced [3] under hypoxia, } \\
\text { depending on species. }\end{array}$ \\
\hline \multirow[t]{2}{*}{ Growth } & $\begin{array}{l}\text { G1. Growth decrease with decreasing DO level, due to } \\
\text { reduction in energy uptake and/or increase in } \\
\text { energy expenditure (dissipation). }\end{array}$ \\
\hline & $\begin{array}{l}\text { G2. Energy allocation reprioritized to first pay } \\
\text { maintenance costs under hypoxic conditions. }\end{array}$ \\
\hline \multirow[t]{3}{*}{ Reproduction } & $\begin{array}{l}\text { R1. Under moderate hypoxia, organisms may continue } \\
\text { to allocate energy to reproduction even if there is no } \\
\text { allocation to structural growth. }\end{array}$ \\
\hline & $\begin{array}{l}\text { R2. Decrease in DO may decrease the gonado-somatic } \\
\text { index. }\end{array}$ \\
\hline & $\begin{array}{l}\text { R3. Hypoxia can disrupt endocrine functions, affecting } \\
\text { gametogenesis, sexual maturity, gamete quality and } \\
\text { fecundity. }\end{array}$ \\
\hline Respiration & $\begin{array}{l}\text { B1. } \mathrm{O}_{2} \text { consumption starts to diminish with a reduced } \\
\mathrm{PO}_{2} \text { below a critical saturation level }\left(\mathrm{PcO}_{2}\right) \text {; when an } \\
\text { animal has an elevated } \mathrm{O}_{2} \text { consumption (swimming, } \\
\text { digesting, etc.), } \mathrm{O}_{2} \text { consumption starts to diminish at } \\
\text { a greater } \mathrm{PO}_{2} \text { than } \mathrm{PcO}_{2} \text {. }\end{array}$ \\
\hline
\end{tabular}

B2. Above $\mathrm{PcO}_{2}$, compensatory mechanisms compensate the $\mathrm{O}_{2}$ reduction to maintain respiration and sustain the standard metabolic rate (increase of $\mathrm{O}_{2}$ conductance: ventilation, heart-beat, $\mathrm{O}_{2}$ affinity for respiratory pigment etc.). These responses can

\section{Empirical evidences}

(Brandt et al., 2009; Chabot and Dutil, 1999; Desai and Prakash, 2009; Le Moullac et al., 2007; Siikavuopio et al., 2007; Sobral and Widdows, 1997; Wang et al., 2011)

[1] (Sobral and Widdows, 1997) [2] (Cheung et al., 2008a) [3] (Chabot, 2001; Wang et al., 2011; Wei et al., 2009; Zhou et al., 2001)

(Chabot and Dutil, 1999; Kramer, 1987)

(Cheung et al., 2008a; Wei et al., 2009; Zhou et al., 2001)

(Cheung et al., 2008a)

(Cheung et al., 2008a; Landry et al., 2007; Long et al., 2013a; Thomas et al., 2006; Wu et al., 2003)

(Landry et al., 2007; Thomas et al., 2006; Wu et al., 2003)

(Artigaud et al., 2014; Claireaux and Chabot, 2016; Claireaux and Lagardère, 1999; Mangum and Winkle, 1973; Schurmann and Steffensen, 1997)

(Bayne, 1971b; Dejours and Beekenkamp, 1977; Herreid II, 1980; Kramer, 1987; Maxime et al., 2000; Racotta et al., 2002; Wei et al., 2009; Wu, 2002a) 
lead to increased $\mathrm{O}_{2}$ consumption (e.g. ventilation rate, heartbeat, mobility).

B3. Behavioural responses under hypoxia can lead to decreased $\mathrm{O}_{2}$ consumption (e.g. reduce activity, reduce feeding) some species may also enter in hypometabolic state for surviving.

B4. Anaerobiosis can start under the $\mathrm{PcO}_{2}$ threshold, with less efficient energy production and toxic endproducts formation (e.g. lactate, acidosis), leading to long-lasting (several hours) imprint on metabolism (oxygen debt).

Survival L1. Lethal DO level and time are different across taxa.

L2. Lethal DO level increase with increasing metabolic activity.

L3. Exponential increase of survival time under anaerobic glycolysis with body mass due to the decrease of mass-specific metabolic rate.
(Herreid II, 1980; Schurmann and Steffensen, 1997; Wei et al., 2009; Wu, 2002a)

(Bayne and Livingstone, 1977; Bridges and Brand, 1980; Nilsson and Östlund-Nilsson, 2008; Nonnotte et al., 1993)

(Vaquer-Sunyer and Duarte, 2011, 2008)

(Valverde et al., 2012)

(Nilsson and Östlund-Nilsson, 2008; Roze et al., 2013; Valverde et al., 2012)

\section{Hypoxia within the DEB theory framework}

\subsection{Conceptual description of the standard DEB model}

An individual is defined by four state variables: reserves $(E$, units: $J)$, structure $(V$, units: $\left.\mathrm{cm}^{3}\right)$, maturity $\left(E_{H}\right.$, units: $\left.\mathrm{J}\right)$, and reproduction $\left(E_{R}\right.$, units: $\left.\mathrm{J}\right)$, and eight metabolic processes: ingestion, assimilation, mobilization, growth, somatic maintenance, maturity maintenance, development and reproduction (Fig 3-1). Life-stage successions are linked with maturity thresholds. Feeding begins when $E_{H}=E_{H}^{b}$ and allocation to reproduction coupled with the cessation of maturation begins when $E_{H}=E_{H}^{p}$. Maintenance has priority over growth and maturity maintenance has priority over maturation or reproduction. The set of equations of the standard DEB model can be found in Kooijman (2010). 


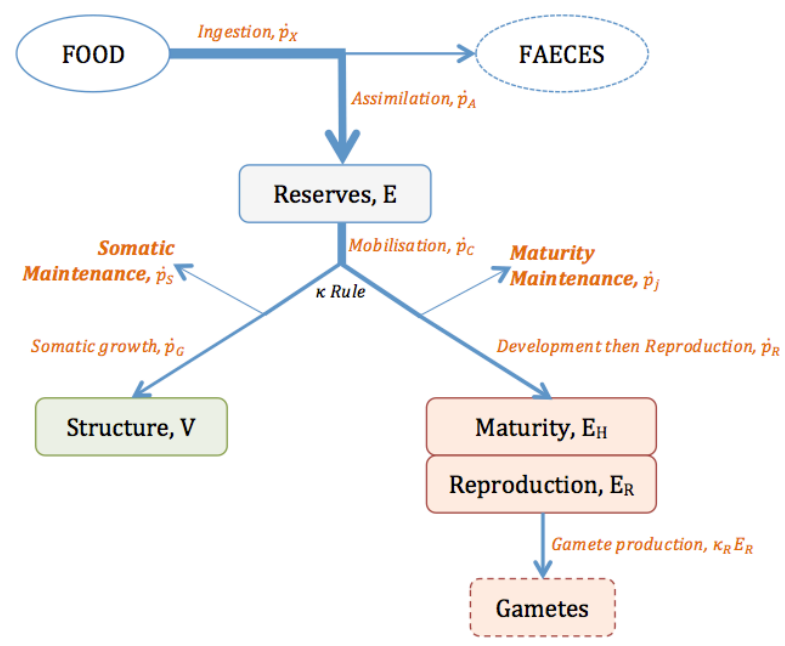

Fig 3-1 Conceptual scheme of the standard DEB model.

\subsection{Assumptions on fluxes modulation under hypoxia}

Within a standard DEB model, responses to hypoxia can be included by acting on various energy fluxes, in relation with the physiological disturbances previously demonstrated:

1. The ingestion rate; organisms reduce their feeding rate with reducing $D O$ (fact F1).

2. The assimilation rate; related to the variation in assimilation efficiency and digestive processes (fact F2).

3. The reserve mobilization rate; related to a lower efficiency of anaerobic metabolism (fact B3)

4. The k-rule and subsequent allocations to growth and reproduction; related to endocrine disruption (facts $\mathrm{G} 2, \mathrm{R} 2, \mathrm{R} 3$ ).

5. The reproductive efficiency; related to the endocrine disruption involved in gametes maturation (fact R3).

6. The somatic maintenance rate; related to a modulation of the maintenance costs (e.g., increased ventilation and/or heartbeat, mobility) (facts D1, D2), and to the lower transformation efficiency for ATP production and by-products elimination under anaerobiosis (fact R3).

7. Death; reduction in energy uptake (facts F1, F2) and increase in metabolic demand (fact B2) can lead to a low level of energy availability, and then to a death threshold when maintenance processes are no longer fuelled. Accumulation of toxic byproducts under anaerobiosis (fact B4) can also cause death (fact L3). Asphyxiation can occur after a period of time under the critical $\mathrm{O}_{2}$ threshold $\left(\mathrm{PcO}_{2}\right)$ (fact $\left.\mathrm{L} 1\right)$. 


\subsection{Dose effect response to hypoxia}

The defining principle of the dose effect of a compound in the DEB model is that some internal concentration affects the value of one or more parameters (e.g. Jager \& Zimmer 2012). For instance, the response to toxicants depends on a no-effect concentration $c_{0}$ and follows an increasing function depending on toxicant concentration $c_{V}$. Similarly, the effect of $\mathrm{DO}$ can be made dependent on a lower threshold of $\mathrm{DO}$, below which targeted physiological functions will be set to zero, and to an increasing function of DO saturation, which ranges between 0 and 1 , corresponding to a range of $0-100 \%$ of DO saturation.

Two examples of such introduction of a dose effect of DO level on DEB fluxes are exposed here in line with two companion papers by Lavaud et al. (subm. this issue) for Atlantic cod and Aguirre-Velarde et al. (subm. this issue) for Peruvian scallop (Argopecten purpuratus) and based on another experimental result on Pacific oyster (Magallana gigas) (Le Moullac et al., 2007). Two different strategies were adopted considering the physiological functions impaired by hypoxic conditions:

- The decrease in energy uptake related to low DO seems to be one of the most sensitive processes, driving the reserves dynamics, growth and reproduction. As exposed by Chabot \& Dutil (1999) for Atlantic cod, $97 \%$ of the reduction in growth was explained by a reduction in the ingestion rate $\left(\dot{p}_{X}\right)$. The same observation was made by Le Moullac et al. (2007) for Pacific oyster. The reduction in the ingestion process restricts entry into reserve through a reduction of the energy available for assimilation. A first application of a dose effect on the ingestion rate was thus included for these two species (see 3.3.1).

- In their study, Aguirre-Velarde et al. (this issue) also considered an effect on food assimilation by modifying assimilation rate $\left(\dot{p}_{A}\right)$. Based on the observation that exposure to hypoxia tended to induce an accumulation of reserves, Aguirre-Velarde et al. (2018) also assumed an effect on reserve mobilization rate $\left(\dot{p}_{c}\right)$. The same oxygen correction function was applied on both fluxes for simplicity's sake. The simultaneous reduction in the assimilation and mobilization fluxes restrict both reserve entry and output (see 3.3.2).

These two applications are presented below.

\subsubsection{Dose effect on ingestion rate}

The effect of DO variations on energetics was included into the DEB model as a correction factor $\left(c_{D O}\right)$, applied to the ingestion rate. The $c_{D O}$ was defined as a function of 
the immediate DO saturation experienced by the organism and was expressed as a saturation function, including a lower critical $D O$ threshold $D O_{\text {crit }}$ as follows:

$c_{D O}(t)= \begin{cases}\alpha \frac{D O(t)-D O_{c r i t}}{\left(D O(t)-D O_{\text {crit }}\right)+\beta} & \text { if } D O(t)>D O_{\text {crit }} \\ 0 & \text { if } D O(t) \leq D O_{\text {crit }}\end{cases}$

with $D O(t)$ the immediate $D O$ saturation, $\alpha(-)$ and $\beta$ (\%sat.) two constants and $D O_{\text {crit }}$ the $D O$ level below which the correction factor is equal to zero. Note that this modelling strategy is close to the immediate effects functions defined by Miller Neilan \& Rose (2014), and applied to the survival, growth and reproduction rates of fish and shrimp, simulated according to allometric relationships. A similar approach, using a sigmoid equation, was also applied to the ingestion, respiration and mortality of macrobenthos by Sturdivant et al. (2013).

The DO correction function $\left(c_{D O}\right)$ parameters were here estimated for $G$. morhua and $M$. gigas on experimental data of ingestion rates, measured at various levels of DO (Chabot and Dutil, 1999; Le Moullac et al., 2007). For G. morhua, experiments were performed at $10^{\circ} \mathrm{C}$ during 90 days, with individual measurements (Chabot and Dutil, 1999). For M. gigas, experiments were performed at three different temperatures (Le Moullac et al., 2007). For the two species, three steps were successively followed for the model calibration: (1) to avoid the effect of individual mass differences, ingestion measurements were scaled for a standard individual of $1 \mathrm{~g}$, according to the following equation: $I_{s}=I_{e}\left(W_{s} / W_{e}\right)^{2 / 3}$, with $I_{s}$ the ingestion rate for an animal at the standard mass, $W_{s}$ the standard mass $(1 \mathrm{~g}), W_{e}$ the observed mass and $l_{e}$ the uncorrected (measured) rate. (2) The result was divided by the Arrhenius temperature correction factor calculated at the experimental temperature in order to set the model at the reference temperature $T_{r e f}=20^{\circ} \mathrm{C}$. (3) Results were finally standardized by the modelling value found at $D O=100 \%$ sat., giving $C_{D O}=1$ at $D O=100 \%$ sat. A nonlinear regression was performed to estimate the function parameters, by using the nonlinear (weighted) least-squares estimates (R function $n / s$ ) (Fig 3-2). A D $\mathrm{O}_{\text {crit }}$ of $30 \%$ sat. was obtained for G. morhua by fitting the curve to the data of Chabot \& Dutil (1999). That agrees with the fact that LC50 was $28 \%$ for this species (Plante et al., 1998). For M. gigas, $D O_{\text {crit }}$ was $18 \%$, in accordance with observed lethal conditions (Lee et al., 2017). 
(a)

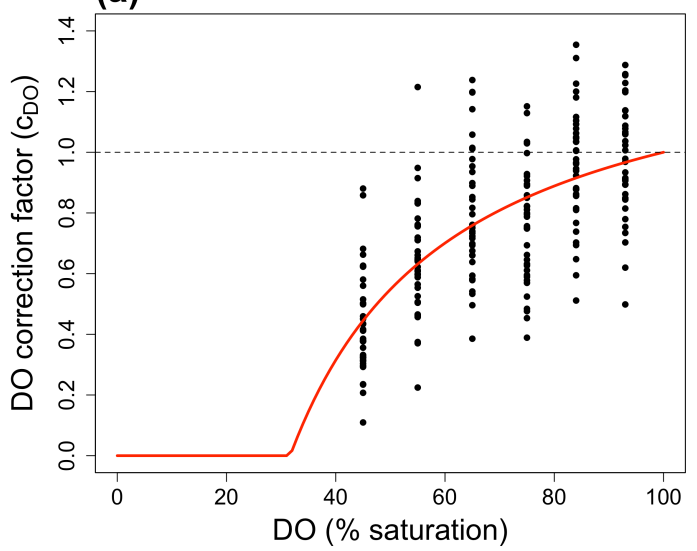

(b)

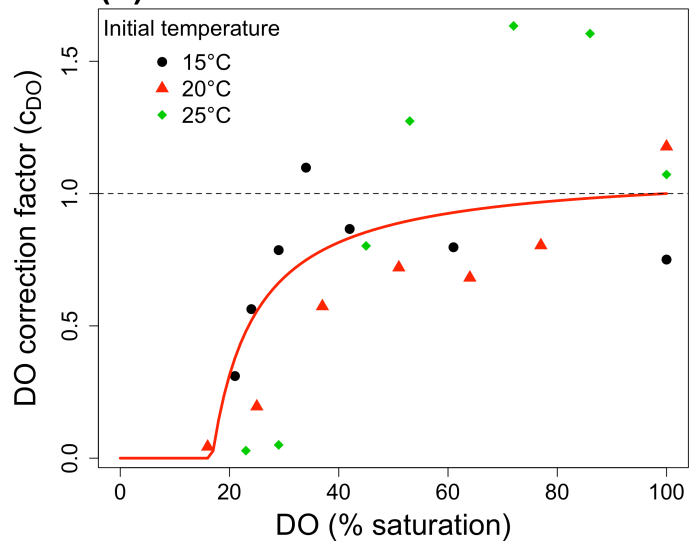

Fig 3-2 Dissolved oxygen correction factor $\left(c_{D O}\right)$ calibrated for (a) Gadus morhua and (b) Magallana gigas, as a function of oxygen saturation. The points are observations, based on individual measurements of ingestion rate (Chabot and Dutil, 1999; Le Moullac et al., 2007) and the line represents the adjusted function.

A step of validation of the $C_{D O}$ function estimation procedure was applied (Fig 3-3). To this end, we used individual growth measurements of Atlantic cod performed by Chabot \& Dutil (1999) during their 90 days experiment. Individual growth simulations were performed using actual DO saturations (i.e. $45,56,65,74,83$ and $93 \%$ ) and temperature $\left(10^{\circ} \mathrm{C}\right.$ ), and results (i.e. simulated mass) were compared to the observations. The same validation step was done for $M$. gigas, based on respiration measurement performed at three different temperatures (Fig 3-3). The Arrhenius function was included in the DEB model to account for the effect of temperature on metabolic fluxes for both species. Observed and simulated mass-specific respiration rate were compared. Both validations show a good agreement between observations and simulations.

(a)

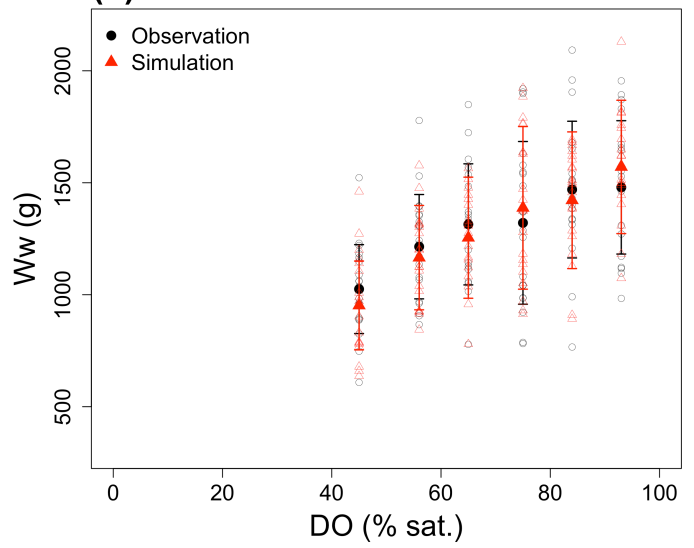

(b)

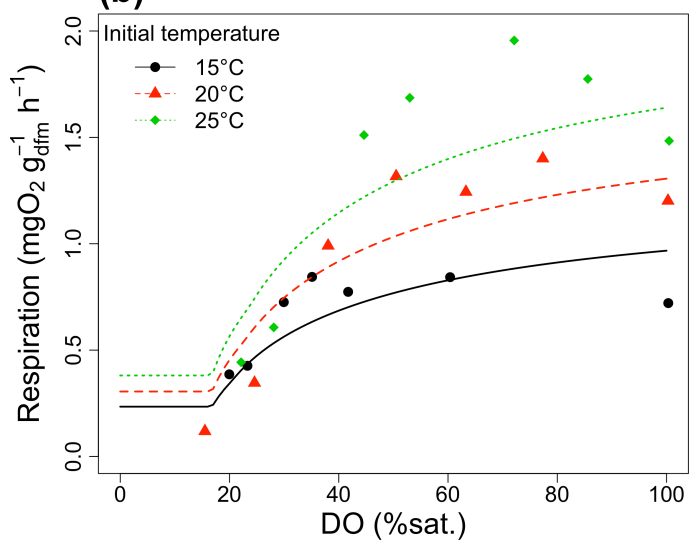

Fig 3-3 Validation of the DO correction factor. (a) body wet mass $(\mathrm{Ww})$ measured at various hypoxia levels after 90 days of experimentation for G. morhua (Chabot and Dutil, 1999) and the corresponding DEB-model simulations including the CDo function. (b) Oxygen consumption simulated (lines) and observed (points) for $M$. gigas; data are scaled for an individual of 1 gram of dry flesh mass (DFM) according to the formula: $\mathrm{MO}_{2} \mathrm{~S}=\mathrm{MO}_{2}(1 / \mathrm{DFM})^{0.75}$. 


\subsubsection{Dose effect on assimilation and mobilization rates}

Based on in-situ measurements of DO saturation in a Peruvian littoral bay naturally affected by hypoxic events (Aguirre-Velarde, 2016), Aguirre-Velarde et al. (subm. this issue) computed time series of an oxygen correction function $c_{D O}$ used to modulate the assimilation and reserve mobilization rates of the Peruvian scallop. Animals were reared at two different depths showing different levels of DO saturation: suspended in the waters column (mild hypoxia) and on the bottom (severe hypoxia) (Fig 3-4). Growth performances observed and simulated were then compared for these two treatments after applying the correction function (Fig 3-5).
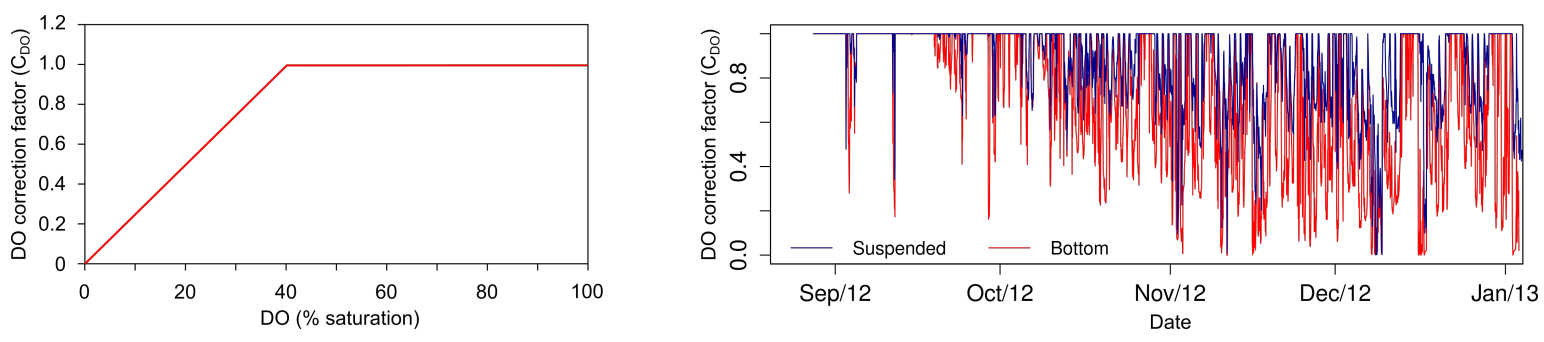

Fig 3-4 DO correction function and resulting temporal evolution of the oxygen correction function applied to the Peruvian scallop assimilation and reserve mobilization rates (modified from Aguirre-Velarde 2016).
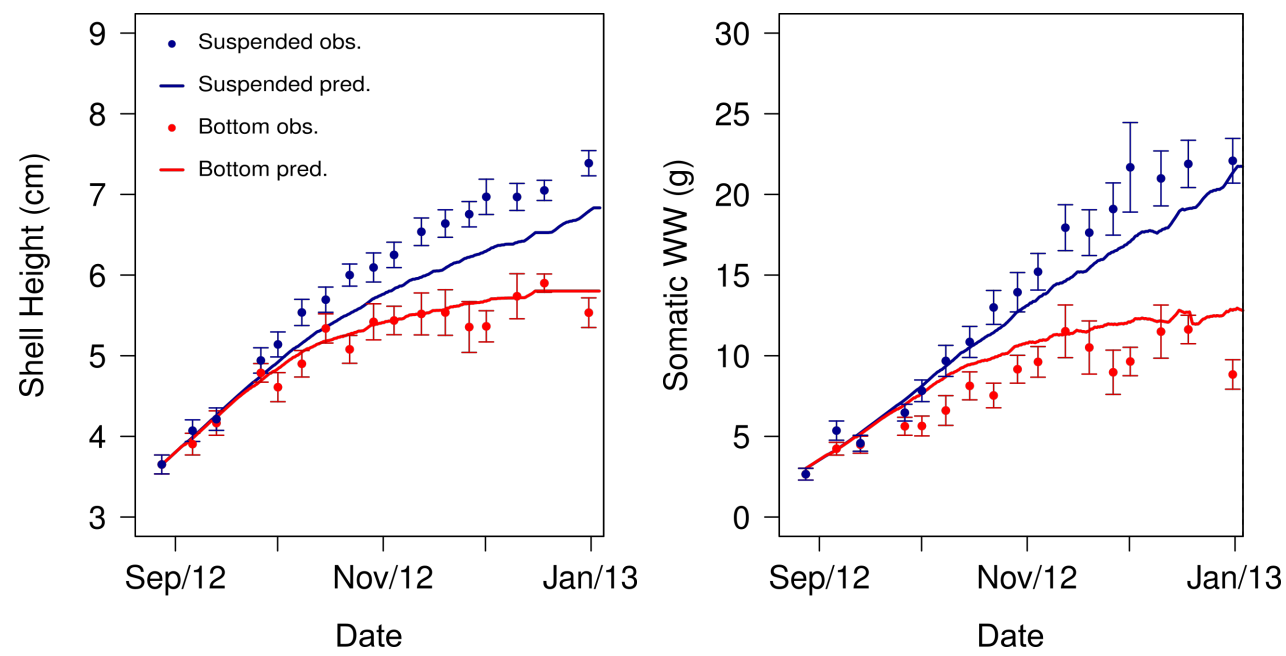

Fig 3-5 Observations (dots) and simulations (lines) of shell height (left) and somatic wet mass (right) of the Peruvian scallop reared in suspended cages and on the bottom in Paracas Bay (from Aguirre-Velarde 2016).

\subsection{Oxygen transport and mass balance in a limited environment}

Our first attempt to introduce the effect of DO variation on energy balance of fish and bivalves was mostly empirical, through the introduction of a correction factor on feeding, assimilation and reserve mobilization rates. This strategy appears to describe the observed pattern in Atlantic cod, Pacific oyster and Peruvian scallop well and is a necessary first step 
towards the development of generic models for the impact of hypoxic conditions on marine organisms (i.e. based on general principles that apply to numerous taxa).

However, many questions need to be addressed to better understand the mechanisms underlying the different impacts and responses to hypoxia and the magnitude of these responses among taxa. We identified the following questions:

- How to deal with oxygen uptake as a limiting substrate?

- How to give priorities among different metabolic processes when oxygen is limiting?

- How to deal with time scales under anaerobic conditions?

We believe that DEB theory provides an ideal framework to address these questions mechanistically. We detail these components in the following paragraphs and highlight the remaining modelling gaps that need to be addressed.

\subsubsection{Oxygen transport within the organism}

In standard DEB, oxygen is a non-limiting substrate. Metabolic processes are therefore not controlled by the uptake of oxygen. Rather, in the DEB framework, oxygen consumption is predicted from metabolic processes such as assimilation, somatic maintenance and growth, and obtained by closing the mass balance for chemical elements (carbon, hydrogen, nitrogen and oxygen) by writing specific macrochemical reactions (see supplementary material for details). The implication is that the use of dioxygen can only be evaluated in combination with the production flux of water, carbon dioxide and nitrogen waste (e.g. ammonia) (Kooijman, 2017). Additional parameters are thus required, such as the elemental composition of the different organic compounds (food, reserve, structure and faeces).

If oxygen becomes limiting, some assumptions of standard DEB no longer apply and new assumptions are required. As described in the previous sections, marine organisms facing decreasing DO conditions may respond by increasing their capacity to extract oxygen from their environment, decrease their requirements to a certain extent, and produce energy using different electron receptors (i.e., anaerobic metabolism).

Among the different behavioural and physiological responses to decreasing oxygen availability, renewing the water surrounding the uptake surface (ventilation), increasing the flow of respiratory pigments (e.g. haemoglobin, hemocyanin) through the ventilatory organs (circulation) and increasing the concentration and affinity of respiratory pigments are often observed. One way to deal with this in the DEB model could be the use of the synthesizing unit (SU) concept. Briefly, the SU are generalised enzymes that follow the rules of classic enzyme kinetics which specifies fluxes of product in term of substrate concentrations. In 
such attempt, the SU could be applied to respiratory pigments with dissolved oxygen in water as a substrate and internal dissolved oxygen at the site where oxygen is consumed as a product. If binding probability is a function of substrate concentration (dissolved oxygen concentration in the layer of water surrounding the uptake surface) and dissociation rate independent of any concentration, we obtain a Michaelis-Menten functional form as for the scaled functional response for food (see One substrate-One product section in the Supplementary Material, and Fig. S1) or $\mathrm{CO}_{2}$ transport in algae (Lorena et al., 2010).

In case of hypoxia, the total oxygen inflow needs to increase. This could be done in two different ways: an increase of the dissociation rate of each SU by increasing circulation rate (e.g. heart beat rate or amplitude), or an increase of the total number of SU by increasing e.g. the total number of respiratory pigments.

\subsubsection{Priorities among demand metabolic processes}

The next set of questions concern the physiological processes that need to be maintained for survival and the remaining processes that can be temporarily reduced (in particular in order to provide energy for increasing the capacity to extract oxygen from water). DEB theory distinguishes demand and supply processes at the time scale of the life cycle of an organism in a standard DEB model. Indeed, movement for the search of food is included into somatic maintenance as it is necessary for survival, development, growth and reproduction. However, movement when an organism faces hypoxic conditions is likely to be a temporary non-essential energy expense (if escape does not appear as a possible strategy). Therefore, we believe that the following priorities could be examined: somatic maintenance is split into an essential fraction (that cannot be reduced) and a non-essential fraction (that can be temporarily reduced, e.g. activity). The essential part of maintenance has first priority for the use of $\mathrm{O}_{2}$ inflow. The non-essential part of these demand fluxes is the next to be able to use the $\mathrm{O}_{2}$ inflow. And finally, the supply processes such as growth, development and reproduction can use the remaining $\mathrm{O}_{2}$ if there is any. Assimilation requires careful attention, as this process is usually predicted in standard DEB over a time (e.g. a day) different to the time required for digestion (e.g. several hours to several days) (W. Zhang et al., 2010). This smooths the specific oxygen requirements referred to as Specific Dynamic Action (SDA), which shape as peaks and hence cannot be paid in smaller amounts over a larger period (Nisbet et al., 2012). Here these oxygen requirements need to be fulfilled. The priority for the use of the $\mathrm{O}_{2}$ flux on assimilation might be speciesdependent. It must use what is left from the essential fraction of maintenance. But there is a need for more research to understand if assimilation or the non-essential fraction of 
maintenance come first, and if there is a general pattern for this priority or if it might differ between species or situations.

The rate at which assimilation can occur given this remaining $\mathrm{O}_{2}$ inflow (once food is ingested, which is also impacted by decreasing $\mathrm{O}_{2}$ as discussed in previous sections) could also be approached with the Synthesizing Unit concept, here with two limiting complementary substrates, food and oxygen, and reserve as product (+ mineral compounds) with parallel binding (i.e. no sequential binding required, the $\mathrm{SU}$ can bind $\mathrm{O}_{2}$ first then food or food first then oxygen). The parallel binding case is developed in Kooijman (2010) and presented in the Supplementary material (section 2 and Fig. S2).

\subsubsection{Time scales and production of reserve under anaerobic conditions}

For survival, organisms also have the ability to produce energy under anaerobic conditions, using different electron receptors. The lower efficiency of the transformation could be taken into account by writing specific macrochemical reactions (defined in the supplementary material) and setting yields coefficients for anaerobic conditions. Kooijman (2010) detailed these transformations for organisms leaving in continuous anaerobic conditions (see book section 4.9). Here, the contributions between the aerobic and the anaerobic routes need to be worked out and may require substantial details (time scales, oxygen debt). In addition, the production of toxic by-products could be considered with a dose-effect function, classically applied in the DEB framework.

These new developments will require dedicated experiments discussed in the following section but the formulation arising from these assumptions is already accessible to evaluate the number of parameters and observables required to estimate these parameters. Qualitative properties of such a model could then be compared with known patterns (e.g. effect of size, variations among taxa) (Verberk et al., 2011).

\section{Future research: Recommendations for coupled experimental and modelling approaches}

Ecophysiology is a science that has its roots in the study of mechanisms (McNab, 2002) and aims to answer the 'how does this work' question. However, as described by Spicer (2014), the physiological responses of species in the wild are not always those predicted from laboratory experiments, in particular because of the behavior and the multiple constraints to which species are subjected. We still "need to make an understanding of how environmental hypoxia affects the physiology of 'wild' marine invertebrates from the 
molecular level up to the whole organism" (Spicer, 2014), to what we could add 'during its entire life cycle'. Further, our understanding of species responses needs to also be scalable to the response at the population level. From our analysis, the temporal scales, ontogenic effects and stressor combination appeared as core issues to deal with and to integrate into a combined experimental and modelling approach.

Temporal scales; as we have seen, hypoxia duration may vary across a wide range of scales, from permanent, persistent seasonal, episodic, to diel. Based on 41 examples of experimental assessment of the effect of hypoxia on marine organisms, we demonstrated that most of them were conducted during very short time scales, typically no more than a few days (Figure 4-1). But tolerance to long-term (weeks) exposure to hypoxic water is still poorly understood (Stickle et al., 1989), even though hypoxia has intensified in severity and duration over the last 60 years (Breitburg et al., 2018). Performing more long-term hypoxia exposure experiments would thus be relevant to be able to describe the response of species in the wild and project e.g. long-term biogeographic scenarios or study the species adaptation potential. Beyond duration, frequency of hypoxia events may interplay on metabolic performances and on the resiliency capacity of species, knowing that species may be submitted to chronic hypoxia (Sturdivant et al., 2013). For example, intermittent hypoxia may strengthen acclimation process reducing the sensitivity to low DO level (Borowiec et al., 2015). During recovery from hypoxia, an $\mathrm{O}_{2}$ debt must be repaid and involves after-effects of anaerobic metabolism, such as lactate elimination. $\mathrm{O}_{2}$ debt has been wildly demonstrated for fish species (Maxime et al., 2000; Nonnotte et al., 1993), and invertebrates (Bayne and Livingstone, 1977; Valverde et al., 2012; Widdows et al., 1979). Patterns of recovery strongly vary between species and within species, from "negative $\mathrm{O}_{2}$ debt" due to alteration of aerobic enzymes during hypoxia, to "supernormal $\mathrm{O}_{2}$ debt" where $\mathrm{O}_{2}$ consumed during recovery exceeds $\mathrm{O}_{2}$ deficit, due to stress or physical activity under hypoxia (Herreid II, 1980). Long-lasting imprint of hypoxia on metabolism and related recovery may thus take several hours, depending on species and hypoxia duration and severity (Bridges and Brand, 1980).

Ontogenic and long-term effects of hypoxia; most of the studies we presented were conducted on adults (i.e. 80\%; Figure 4-1). However, coastal habitats, which are increasingly subjected to hypoxic episodes, often serve as nursery grounds for juvenile and larval life-history stages. If we consider the crucial importance of these early stages in population dynamics, understanding the consequences of hypoxia on their physiology appears to be a determining factor (e.g., impact of a reduced growth rate of juveniles on population dynamics, duration of the period when juveniles are susceptible to predation, 
etc.) (Dupont-Prinet et al., 2013b). Moreover, there is evidence that exposure to low oxygen conditions at an early life stage may have long-lasting impact on species physiology (Vanderplancke et al., 2015), as exposure to high temperature conditions during the larval stage may enhance resistance to hypoxia at juvenile stages (Zambonino-Infante et al., 2013). Integrating the effects of hypoxia throughout the life cycle of organisms is therefore crucial to anticipate the response of species in the wild. The long-lasting imprint of earlystage exposure remain challenging within a modelling perspective. The DEB theory takes into account the full life-cycle of organisms, which offers valuable perspectives in integrating the effects of stressors applied at early life on the subsequent developmental stages.
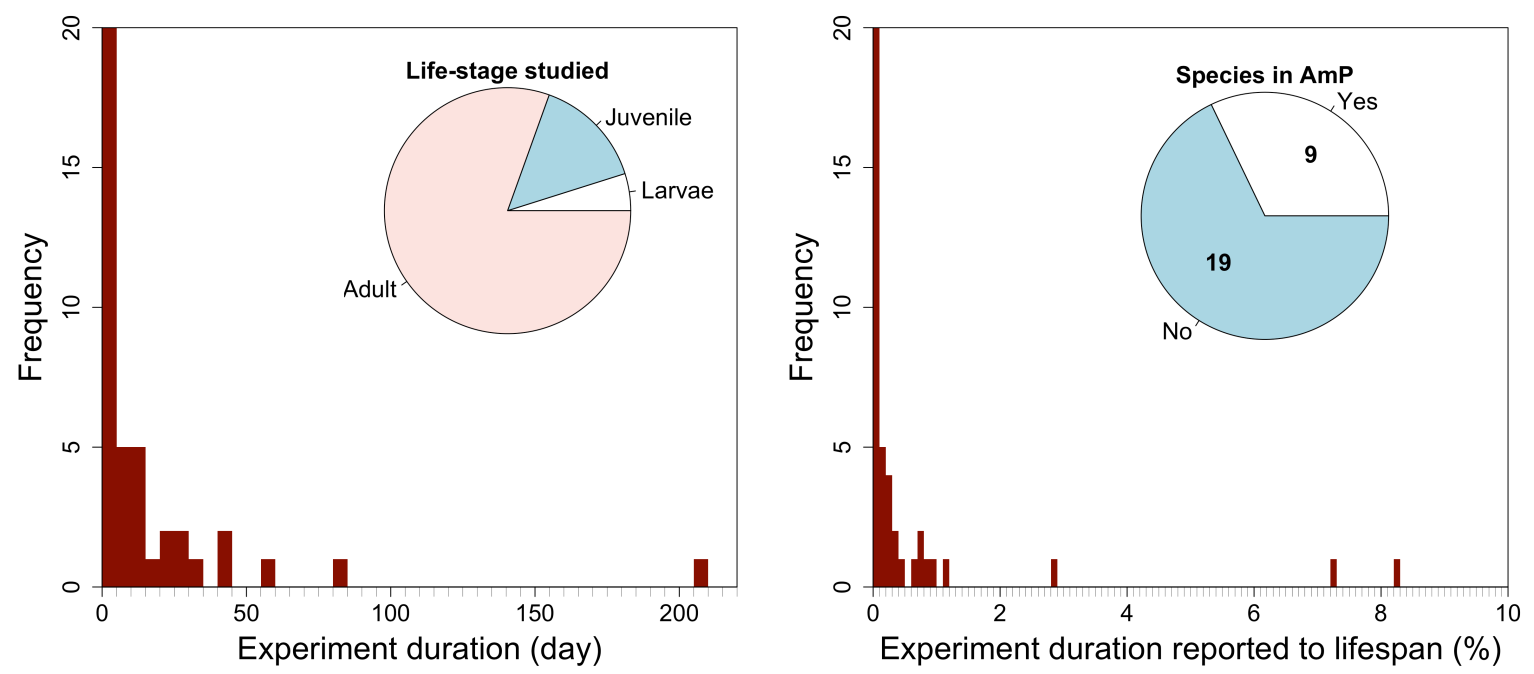

Figure 4-1 Frequency distribution of the experiment duration in day (left) and reported to the species' lifespan (right). Pie charts give the proportion of ontogenic stages studied (left) and of the species having an entry in the Add my Pet (AmP) collection (right), within the 41 examples found in the literature cited in the present study (total of 28 species).

Response to multiple stressors; Hypoxia caused by organic pollution is often associated with other environmental disturbances (warming, increase in ammonia, hydrogen sulphide, load of particulate organic matter, low pH etc.) (Burnett, 1997; Wu, 2002a). Synergistic effects are thus described between hypoxia and other environmental variables such as the temperature and hypercapnia (Melzner et al., 2013; Pörtner et al., 2005; Rosa et al., 2013). This should be taken into account to properly understand the response of species in the wild. For example, hypoxia is hypothesized to affect species' thermal tolerance by reducing the width of the thermal performance breadth and by decreasing aerobic performances (Fry, 1971; Pörtner, 2010; Verberk and Bilton, 2011). When temperatures increased, species' oxyregulatory capacity is compromised (i.e. increase in $\mathrm{PcO}_{2}$ value) alongside a reduction in aerobic performance (Artigaud et al., 2014; Schurmann and Steffensen, 1997). The standard DEB model allows to take into account the additive effects of multiple stressors (e.g. warming, starvation, hypoxia). As exposed in 
assessing toxic effects of mixtures in the framework of DEB theory (Baas et al., 2010), we now need to deal with non-additive (e.g. synergistic) effects of environmental variables, potentially acting on the shape of the response curves, such as the Arrhenius function (i.e. temperature effect) or functional response (i.e. food effect).

Combining experimental and modelling approaches; Going from the knowledge acquired through experimentation to the response in nature remains a challenge and "stepping from the real world into the abstract one, and back again" (Kooijman, 2017) is also really challenging when one deals with modelling approaches. As shown by the empirical cycle presented by Kooijman (2017), experimentation and modelling are closely related since there is a need to implement an integrated approach between observations, the formulation of hypotheses, the formulation and derivation of mechanistic assumptions, and the design of experiments. This cycle approach in studying the effect of stressors is particularly challenging and necessitates the collaboration of (at least) two communities of eco-physiologists and modelers, who may have significant differences in terms of language, technical constraints and expectations. To date, there is a growing number of examples of this type of integrated approach between experimentation and modelling. Moreover, new technical developments, such as -omics approaches, offer the possibility of a comprehensive understanding of the response to stressors and its mechanistic formulation (David et al., 2005; Sussarellu et al., 2016).

A good practice in experimental work is to have a control, without the target substance or with no-stress conditions. By analogy, modelling the target species metabolism in standard conditions, without stress, is needed. Indeed, this "null-model" is a necessary first step to go forward when dealing with modelling the effect of stressors on metabolic functions. Then, there are many ways in which a model may incorporate the effect of stressors. The DEB model has a limited number of parameters directly related to processes controlling state variables dynamics and a few number of auxiliary parameters which link these variables to quantities that can be measured directly (e.g. length, wet or dry mass, respiration, egg output) (van der Meer, 2006). This allows to link abstract and real worlds (Lika et al., 2011), and offers the opportunity to act on a limited number of parameters to properly introduce the effect of stressors in the model, and thus to limit complexity. We highlighted 7 points on how oxygen may affect DEB processes (see section 3.2). But there is a need for parsimonious modelling strategies, which do not include all the possibilities. We thus explored empirical evidences to hierarchize the processes impaired under hypoxia, and focused on the effect on energy uptake, which explain most of the observed response for the studied species. 


\section{Conclusion}

In this paper, we proposed a set of stylized biological facts sustaining the establishment of assumptions in the frame of the DEB theory about the effects of hypoxia on metabolic pathways in marine organisms. Then, we validated some of these assumptions on three marine species. As we are still within the loop of the empirical cycle (sensu Kooijman 2017), further work is needed in order to mechanistically formulate our assumptions. But models' relevance will also depend on their simplicity. By combining the effect of several stressors on species metabolic performances and life-history traits across their full life-cycle, the DEB model offers a promising framework for future work studying the consequences of hypoxia, and its interaction with other stressors, on marine organisms. In such an attempt, dealing with the various time-scales, ontogenic response and multiple stressor effects appears now as important targets of investigation.

\section{Acknowledgments}

This work was supported by LabexMer French project (ANR-10-LABX-19-01). Part of this work arise from the international workshop on "Combining Modeling and Experimental Approaches for Marine Organisms under Stress" in 2016 at the European Institute for Marine Studies, Brest, France. 


\section{References}

Aguirre-Velarde, A., 2016. Bioenergetics of the Peruvian scallops (Argopecten purpuratus) in an environmental context limiting oxygen. PhD thesis, Université de Bretagne Occidentale.

Aguirre-Velarde, A., Jean, F., Thouzeau, G., Flye-Sainte-Marie, J., 2018. Feeding behaviour and growth of the Peruvian scallop (Argopecten purpuratus) under daily cyclic hypoxia conditions. J. Sea Res. 131, 85-94. https://doi.org/10.1016/j.seares.2017.11.001

Aguirre-Velarde, A., Jean, F., Thouzeau, G., Pecquerie, L., Flye-Sainte-Marie, J., this issue. Predicting the energy budget of the scallop Argopecten purpuratus in an oxygenlimiting environment. J. Sea Res.

Artigaud, S., Lacroix, C., Pichereau, V., Flye-Sainte-Marie, J., 2014. Respiratory response to combined heat and hypoxia in the marine bivalves Pecten maximus and Mytilus spp. Comp. Biochem. Physiol. A Mol. Integr. Physiol. 175, 135-140. https://doi.org/10.1016/j.cbpa.2014.06.005

Baas, J., Jager, T., Kooijman, B., 2010. A review of DEB theory in assessing toxic effects of mixtures. Sci. Tot. Env. 408, 3740-3745. https://doi.org/10.1016/j.scitotenv.2009.09.037

Baker, S.M., Mann, R., 1994. Feeding ability during settlement and metamorphosis in the oyster Crassostrea virginica (Gmelin, 1791) and the effects of hypoxia on postsettlement ingestion rates. Journal of Experimental Marine Biology and Ecology 181, 239-253.

Bayne, B., 1973. The responses of three species of bivalve mollusc to declining oxygen tension at reduced salinity. Comparative Biochemistry and Physiology Part A: Physiology 45, 793-806. https://doi.org/10.1016/0300-9629(73)90082-0

Bayne, B.L., 1971a. Oxygen consumption by three species of lamellibranch mollusc in declining ambient oxygen tension. Comparative Biochemistry and Physiology Part A: Physiology 40, 955-970. https://doi.org/10.1016/0300-9629(71)90284-2

Bayne, B.L., 1971b. Ventilation, the heart beat and oxygen uptake by Mytilus edulis L. in declining oxygen tension. Comparative Biochemistry and Physiology Part A: Physiology 40, 1065-1085. https://doi.org/10.1016/0300-9629(71)90295-7

Bayne, B.L., Livingstone, D.R., 1977. Responses of Mytilus edulis L. to low oxygen tension: Acclimation of the rate of oxygen consumption. J Comp Physiol B 114, 129-142. https://doi.org/10.1007/BF00688964

Borowiec, B.G., Darcy, K.L., Gillette, D.M., Scott, G.R., 2015. Distinct physiological strategies are used to cope with constant hypoxia and intermittent hypoxia in killifish (Fundulus heteroclitus). J. Exp. Biol. 218, 1198-1211. https://doi.org/10.1242/jeb.114579

Brandt, S.B., Gerken, M., Hartman, K.J., Demers, E., 2009. Effects of hypoxia on food consumption and growth of juvenile striped bass (Morone saxatilis). J. Exp. Mar. Biol. Ecol. 381, Supplement, S143-S149. https://doi.org/10.1016/j.jembe.2009.07.028

Breitburg, D., Levin, L.A., Oschlies, A., Grégoire, M., Chavez, F.P., Conley, D.J., Garçon, V., Gilbert, D., Gutiérrez, D., Isensee, K., Jacinto, G.S., Limburg, K.E., Montes, I., Naqvi, S.W.A., Pitcher, G.C., Rabalais, N.N., Roman, M.R., Rose, K.A., Seibel, B.A., 
Telszewski, M., Yasuhara, M., Zhang, J., 2018. Declining oxygen in the global ocean and coastal waters. Science 359. https://doi.org/10.1126/science.aam7240

Bridges, C.., Brand, A.., 1980. The effect of hypoxia on oxygen consumption and blood lactate levels of some marine crustacea. Comparative Biochemistry and Physiology Part A: Physiology 65, 399-409. https://doi.org/10.1016/0300-9629(80)90051-1

Burnett, L.E., 1997. The Challenges of Living in Hypoxic and Hypercapnic Aquatic Environments. Amer. Zool. 37, 633-640. https://doi.org/10.1093/icb/37.6.633

Chabot, D., 2001. Impact of chronic hypoxia on food ingestion, growth and condition of Atlantic cod, Gadus morhua (No. ICES CM 2001/ V:05).

Chabot, D., Claireaux, G., 2008. Environmental hypoxia as a metabolic constraint on fish: The case of Atlantic cod, Gadus morhua. Marine Pollution Bulletin 57, 287-294. https://doi.org/10.1016/j.marpolbul.2008.04.001

Chabot, D., Dutil, J.-D., 1999. Reduced growth of Atlantic cod in non-lethal hypoxic conditions. J. Fish Biol. 55, 472-491. https://doi.org/10.1111/j.10958649.1999.tb00693.x

Cheung, S.G., Chan, H.Y., Liu, C.C., Shin, P.K.S., 2008a. Effect of prolonged hypoxia on food consumption, respiration, growth and reproduction in marine scavenging gastropod Nassarius festivus. Mar. Pol. Bul. 57, 280-286. https://doi.org/10.1016/j.marpolbul.2008.03.039

Cheung, S.G., Chan, H.Y., Liu, C.C., Shin, P.K.S., 2008b. Effect of prolonged hypoxia on food consumption, respiration, growth and reproduction in marine scavenging gastropod Nassarius festivus. Marine Pollution Bulletin 57, 280-286. https://doi.org/10.1016/j.marpolbul.2008.03.039

Claireaux, G., Chabot, D., 2016. Responses by fishes to environmental hypoxia: integration through Fry's concept of aerobic metabolic scope. J Fish Biol 88, 232-251. https://doi.org/10.1111/jfb.12833

Claireaux, G., Lagardère, J.-P., 1999. Influence of temperature, oxygen and salinity on the metabolism of the European sea bass. Journal of Sea Research 42, 157-168. https://doi.org/10.1016/S1385-1101(99)00019-2

David, E., Tanguy, A., Pichavant, K., Moraga, D., 2005. Response of the Pacific oyster Crassostrea gigas to hypoxia exposure under experimental conditions. FEBS Journal 272, 5635-5652. https://doi.org/10.1111/j.1742-4658.2005.04960.x

Dejours, P., Beekenkamp, H., 1977. Crayfish respiration as a function of water oxygenation. Respiration Physiology 30, 241-251. https://doi.org/10.1016/0034-5687(77)900330

Desai, D.V., Prakash, S., 2009. Physiological responses to hypoxia and anoxia in Balanus amphitrite (Cirripedia: Thoracica). Mar. Ecol. Prog. Ser. 390, 157-166.

Deutsch, C., Ferrel, A., Seibel, B., Pörtner, H.-O., Huey, R.B., 2015. Climate change tightens a metabolic constraint on marine habitats. Science 348, 1132-1135. https://doi.org/10.1126/science.aaa1605

Diaz, R.J., Rosenberg, R., 2008. Spreading Dead Zones and Consequences for Marine Ecosystems. Science 321, 926-929. https://doi.org/10.1126/science.1156401

Domenici, P., Lefrançois, C., Shingles, A., 2007. Hypoxia and the antipredator behaviours of fishes. Philos. Trans. R. Soc. Lond. B Biol. Sci. 362, 2105. https://doi.org/10.1098/rstb.2007.2103 
Dupont-Prinet, A., Pillet, M., Chabot, D., Hansen, T., Tremblay, R., Audet, C., 2013a. Northern shrimp (Pandalus borealis) oxygen consumption and metabolic enzyme activities are severely constrained by hypoxia in the Estuary and Gulf of St. Lawrence. J. Exp. Mar. Biol. Ecol. 448, 298-307. https://doi.org/10.1016/j.jembe.2013.07.019

Dupont-Prinet, A., Vagner, M., Chabot, D., Audet, C., 2013b. Impact of hypoxia on the metabolism of Greenland halibut (Reinhardtius hippoglossoides). Can. J. Fish. Aquat. Sci. 70, 461-469. https://doi.org/10.1139/cjfas-2012-0327

Ekau, W., Auel, H., Pörtner, H.-O., Gilbert, D., 2010. Impacts of hypoxia on the structure and processes in pelagic communities (zooplankton, macro-invertebrates and fish). Biogeosciences 7, 1669-1699. https://doi.org/10.5194/bg-7-1669-2010

Fry, F.E.J., 1971. The effect of environemental factors on the physiology of fish, In: W.S. Hoar \& D.J. Randall (ed.) Fish Physiology. Vol 6, Academic Press, New York. ed.

Garcia, H.E., Gordon, L.I., 1992. Oxygen solubility in seawater: Better fitting equations. Limnol. Oceanogr. 37, 1307-1312. https://doi.org/10.4319/lo.1992.37.6.1307

Gilbert, D., Rabalais, N.N., Díaz, R.J., Zhang, J., 2010. Evidence for greater oxygen decline rates in the coastal ocean than in the open ocean. Biogeosciences 7, 2283-2296. https://doi.org/10.5194/bg-7-2283-2010

Grall, J., Chauvaud, L., 2002. Marine eutrophication and benthos: the need for new approaches and concepts. Global Change Biology 8, 813-830. https://doi.org/10.1046/j.1365-2486.2002.00519.x

Gray, J.S., Wu, R.S., Or, Y.Y., 2002. Effects of hypoxia and organic enrichment on the coastal marine environment. Mar Ecol Prog Ser 238, 249-279.

Hartman, K.J., Brandt, S.B., 1995. Comparative energetics and the development of bioenergetics models for sympatric estuarine piscivores. Can. J. Fish. Aquat. Sci. 52, 1647-1666. https://doi.org/10.1139/f95-759

Haure, J., Huvet, A., Palvadeau, H., Nourry, M., Penisson, C., Martin, J.L.., Boudry, P., 2003. Feeding and respiratory time activities in the cupped oysters Crassostrea gigas, Crassostrea angulata and their hybrids. Aquaculture 218, 539-551. https://doi.org/10.1016/S0044-8486(02)00493-3

Helly, J.J., Levin, L.A., 2004. Global distribution of naturally occurring marine hypoxia on continental margins. Deep Sea Research Part I: Oceanographic Research Papers 51, 1159-1168. https://doi.org/10.1016/j.dsr.2004.03.009

Herreid II, C.F., 1980. Hypoxia in invertebrates. Comp. Biochem. Physiol. A Physiol. 67, 311-320. https://doi.org/10.1016/S0300-9629(80)80002-8

Hochachka, P., 1986. Defense strategies against hypoxia and hypothermia. Science 231, 234. https://doi.org/10.1126/science.2417316

Jager, T., Zimmer, E.I., 2012. Simplified Dynamic Energy Budget model for analysing ecotoxicity data. Ecol. Model. 225, 74-81. https://doi.org/10.1016/j.ecolmodel.2011.11.012

Jordan, A.D., Steffensen, J.F., 2007. Effects of Ration Size and Hypoxia on Specific Dynamic Action in the Cod. Physiol. Biochem. Zool. 80, 178-185. https://doi.org/10.1086/510565

Keeling, R.F., Körtzinger, A., Gruber, N., 2009. Ocean Deoxygenation in a Warming World. Annu. Rev. Marine. Sci. 2, 199-229. https://doi.org/10.1146/annurev.marine.010908.163855 
Kemp, W.M., Testa, J.M., Conley, D.J., Gilbert, D., Hagy, J.D., 2009. Temporal responses of coastal hypoxia to nutrient loading and physical controls. Biogeosciences 6, 2985-3008. https://doi.org/10.5194/bg-6-2985-2009

Kooijman, S.A.L.M., 2017. Models in stress research. Ecol. Complex. https://doi.org/10.1016/j.ecocom.2017.07.006

Kooijman, S.A.L.M., 2014. Metabolic acceleration in animal ontogeny: An evolutionary perspective. J. Sea Res. 94, 128-137. https://doi.org/10.1016/j.seares.2014.06.005

Kooijman, S.A.L.M., 2010. Dynamic Energy Budget Theory for Metabolic Organisation. Cambridge University Press, Cambridge.

Kramer, D., 1987. Dissolved oxygen and fish behavior. Environ. Biol. Fish. 18, 81-92. https://doi.org/10.1007/BF00002597

Landry, C.A., Steele, S.L., Manning, S., Cheek, A.O., 2007. Long term hypoxia suppresses reproductive capacity in the estuarine fish, Fundulus grandis. Comparative Biochemistry and Physiology Part A: Molecular \& Integrative Physiology 148, 317323. https://doi.org/10.1016/j.cbpa.2007.04.023

Lavaud, R., Thomas, Y., Pecquerie, L., Benoît, H.P., Guyondet, T., Flye-Sainte-Marie, J., Chabot, D., this issue. Modeling the impact of hypoxia on the energy budget of Atlantic cod in two populations of the Gulf of Saint-Lawrence, Canada. J. Sea Res.

Le Moullac, G., Quéau, I., Le Souchu, P., Pouvreau, S., Moal, J., René Le Coz, J., François Samain, J., 2007. Metabolic adjustments in the oyster Crassostrea gigas according to oxygen level and temperature. Mar. Biol. Res. 3, 357-366. https://doi.org/10.1080/17451000701635128

Lee, S.J., Jo, Q., Han, J.C., Park, Y.C., Park, T.G., 2017. Pelagic oxycline and damage potential of hypoxia to the Pacific oyster Crassostrea gigas suspended in longline aquaculture systems. Aquacult. Environ. Interact. 9, 461-468.

Lefevre, S., McKenzie, D.J., Nilsson, G.E., 2017. Models projecting the fate of fish populations under climate change need to be based on valid physiological mechanisms. Glob. Change Biol. 23, 3449-3459. https://doi.org/10.1111/gcb.13652

Lichtschlag, A., Donis, D., Janssen, F., Jessen, G.L., Holtappels, M., Wenzhöfer, F., Mazulmyan, S., Sergeeva, N., Waldmann, C., Boetius, A., 2015. Effects of fluctuating hypoxia on benthic oxygen consumption in the Black Sea (Crimean Shelf). Biogeosciences Discuss. 12, 6445-6488. https://doi.org/10.5194/bgd-126445-2015

Lika, K., Kearney, M.R., Freitas, V., van der Veer, H.W., van der Meer, J., Wijsman, J.W.M., Pecquerie, L., Kooijman, S.A.L.M., 2011. The "covariation method" for estimating the parameters of the standard Dynamic Energy Budget model I: Philosophy and approach. Journal of Sea Research 66, 270-277. https://doi.org/10.1016/j.seares.2011.07.010

Long, W.C., Seitz, R.D., Brylawski, B.J., Lipcius, R.N., 2013a. Individual, population, and ecosystem effects of hypoxia on a dominant benthic bivalve in Chesapeake Bay. Ecol. Monogr. 84, 303-327. https://doi.org/10.1890/13-0440.1

Long, W.C., Seitz, R.D., Brylawski, B.J., Lipcius, R.N., 2013b. Individual, population, and ecosystem effects of hypoxia on a dominant benthic bivalve in Chesapeake Bay. Ecological Monographs 84, 303-327. https://doi.org/10.1890/13-0440.1

Lorena, A., Marques, G.M., Kooijman, S.A.L.M., Sousa, T., 2010. Stylized facts in microalgal growth: interpretation in a dynamic energy budget context. Philos. Trans. R. Soc. Lond. B Biol. Sci. 365, 3509. https://doi.org/10.1098/rstb.2010.0101 
Mangum, C., Winkle, W. van, 1973. Responses of Aquatic Invertebrates to Declining Oxygen Conditions. American Zoologist 13, 529-541. https://doi.org/10.1093/icb/13.2.529

Martin, B.T., Jager, T., Nisbet, R.M., Preuss, T.G., Grimm, V., 2013. Predicting Population Dynamics from the Properties of Individuals: A Cross-Level Test of Dynamic Energy Budget Theory. The Amer. Nat. 181, 506-519. https://doi.org/10.1086/669904

Maxime, V., Pichavant, K., Boeuf, G., Nonnotte, G., 2000. Effects of hypoxia on respiratory physiology of turbot, Scophthalmus maximus. Fish Physiology and Biochemistry 22, 51-59. https://doi.org/10.1023/A:1007829214826

McNab, B.K., 2002. The Physiological Ecology of Vertebrates: A View from Energetics., Comstock Publishing Associates, Cornell University Press, Ithaca, New York, 576 pp.

Melzner, F., Thomsen, J., Koeve, W., Oschlies, A., Gutowska, M.A., Bange, H.W., Hansen, H.P., Körtzinger, A., 2013. Future ocean acidification will be amplified by hypoxia in coastal habitats. Mar. Biol. 160, 1875-1888. https://doi.org/10.1007/s00227-0121954-1

Miller Neilan, R., Rose, K., 2014. Simulating the effects of fluctuating dissolved oxygen on growth, reproduction, and survival of fish and shrimp. Journal of Theoretical Biology 343, 54-68. https://doi.org/10.1016/j.jtbi.2013.11.004

Nelson, J.A., 2016. Oxygen consumption rate v. rate of energy utilization of fishes: a comparison and brief history of the two measurements. Journal of Fish Biology 88, 10-25. https://doi.org/10.1111/jfb.12824

Nilsson, G.E., Östlund-Nilsson, S., 2008. Does size matter for hypoxia tolerance in fish? Biological Reviews 83, 173-189. https://doi.org/10.1111/j.1469-185X.2008.00038.x

Nisbet, R.M., Jusup, M., Klanjscek, T., Pecquerie, L., 2012. Integrating dynamic energy budget (DEB) theory with traditional bioenergetic models. J. Exp. Biol. 215, 892. https://doi.org/10.1242/jeb.059675

Nonnotte, G., Maxime, V., Truchot, J.P., Williot, P., Peyraud, C., 1993. Respiratory responses to progressive ambient hypoxia in the sturgeon, Acipenser baeri. Respiration Physiology 91, 71-82. https://doi.org/10.1016/0034-5687(93)90090-W

Norkko, J., Pilditch, C.A., Thrush, S.F., Wells, R.M.G., 2005. Effects of food availability and hypoxia on bivalves: the value of using multiple parameters to measure bivalve condition in environmental studies. Mar Ecol Prog Ser 298, 205-218.

Ott, M.E., Heisler, N., Ultsch, G.R., 1980. A re-evaluation of the relationship between temperature and the critical oxygen tension in freshwater fishes. Comp. Biochem. Physiol. A Physiol. 67, 337-340. https://doi.org/10.1016/S0300-9629(80)80005-3

Pauly, D., Cheung, W.W.L., 2018. Sound physiological knowledge and principles in modeling shrinking of fishes under climate change. Glob. Change Biol. 24, e15-e26. https://doi.org/10.1111/gcb.13831

Pichavant, K., Person-Le-Ruyet, J., Bayon, N.L., Severe, A., Roux, A.L., Boeuf, G., 2001. Comparative effects of long-term hypoxia on growth, feeding and oxygen consumption in juvenile turbot and European sea bass. Journal of Fish Biology 59, 875-883. https://doi.org/10.1111/j.1095-8649.2001.tb00158.x

Pichavant, K., Person-Le-Ruyet, J., Le Bayon, N., Sévère, A., Le Roux, A., Quéméner, L., Maxime, V., Nonnotte, G., Boeuf, G., 2000. Effects of hypoxia on growth and metabolism of juvenile turbot. Aquaculture 188, 103-114. https://doi.org/10.1016/S0044-8486(00)00316-1 
Plante, S., Chabot, D., Dutil, J.-D., 1998. Hypoxia tolerance in Atlantic cod. J. Fish Biol. 53, 1342-1356. https://doi.org/10.1111/j.1095-8649.1998.tb00253.x

Pörtner, H.-O., 2010. Oxygen- and capacity-limitation of thermal tolerance: a matrix for integrating climate-related stressor effects in marine ecosystems. J. Exp. Biol. 213, 881-893. https://doi.org/10.1242/jeb.037523

Pörtner, H.O., Grieshaber, M.K., 1993. Critical PCO2 (s) in oxyconforming and oxyregulating animals: gas exchange, metabolic rate and the mode of energy production, Bicudo, J. E. P. W., CRC Press Inc., Boca Raton FL, USA. ed, The vertebrate gas transport cascade: adaptations to environment and mode of life.

Pörtner, H.O., Langenbuch, M., Michaelidis, B., 2005. Synergistic effects of temperature extremes, hypoxia, and increases in $\mathrm{CO} 2$ on marine animals: From Earth history to global change. J. Geophys. Res. 110, n/a-n/a. https://doi.org/10.1029/2004JC002561

Rabalais, N.N., Díaz, R.J., Levin, L.A., Turner, R.E., Gilbert, D., Zhang, J., 2010. Dynamics and distribution of natural and human-caused hypoxia. Biogeosciences 7, 585-619. https://doi.org/10.5194/bg-7-585-2010

Racotta, I.S., Palacios, E., MÉndez, L., 2002. Metabolic responses to short and long-term exposure to hypoxia in white shrimp (Penaeus vannamei). Marine and Freshwater Behaviour and Physiology 35, 269-275. https://doi.org/10.1080/1023624021000019333

Rosa, R., Trübenbach, K., Repolho, T., Pimentel, M., Faleiro, F., Boavida-Portugal, J., Baptista, M., Lopes, V.M., Dionísio, G., Leal, M.C., Calado, R., Pörtner, H.O., 2013. Lower hypoxia thresholds of cuttlefish early life stages living in a warm acidified ocean. Proc. Roy. Soc. Lond. B Biol. Sci. 280. https://doi.org/10.1098/rspb.2013.1695

Roze, T., Christen, F., Amerand, A., Claireaux, G., 2013. Trade-off between thermal sensitivity, hypoxia tolerance and growth in fish. Journal of Thermal Biology 38, 98106. https://doi.org/10.1016/j.jtherbio.2012.12.001

Schurmann, H., Steffensen, J.F., 1997. Effects of temperature, hypoxia and activity on the metabolism of juvenile Atlantic cod. J. Fish Biol. 50, 1166-1180. https://doi.org/10.1111/j.1095-8649.1997.tb01645.x

Siikavuopio, S.I., Dale, T., Mortensen, A., Foss, A., 2007. Effects of hypoxia on feed intake and gonad growth in the green sea urchin, Strongylocentrotus droebachiensis. Aquaculture 266, 112-116. https://doi.org/10.1016/j.aquaculture.2007.02.028

Sobral, P., Widdows, J., 1997. Influence of hypoxia and anoxia on the physiological responses of the clam Ruditapes decussatus from southern Portugal. Mar. Biol. 127, 455-461. https://doi.org/10.1007/s002270050033

Sousa, T., Domingos, T., Kooijman, S.A.L.., 2008. From empirical patterns to theory: a formal metabolic theory of life. Philosophical Transactions of the Royal Society of London B: Biological Sciences 363, 2453-2464. https://doi.org/10.1098/rstb.2007.2230

Sousa, T., Domingos, T., Poggiale, J.-C., Kooijman, S.A.L.M., 2010. Dynamic energy budget theory restores coherence in biology. Philos. Trans. R. Soc. B-Biol. Sci. 365, $3413-3428$.

Spicer, J.I., 2014. What can an ecophysiological approach tell us about the physiological responses of marine invertebrates to hypoxia? J. Exp. Biol. 217, 46. https://doi.org/10.1242/jeb.090365 
Spoek, G.L., 1974. The relationship between blood haemocyanin level, oxygen uptake, and the heart-beat and scaphognathite-beat frequencies in the lobster homarus gammarus. Netherlands Journal of Sea Research 8, 1-26. https://doi.org/10.1016/0077-7579(74)90024-6

Stickle, W.B., Kapper, M.A., Liu, L.-L., Gnaiger, E., Wang, S.Y., 1989. Metabolic Adaptations of Several Species of Crustaceans and Molluscs to Hypoxia: Tolerance and Microcalorimetric Studies. Biol. Bull. 177, 303-312.

Stierhoff, K.L., Targett, T.E., Miller, K., 2006. Ecophysiological responses of juvenile summer and winter flounder to hypoxia: experimental and modeling analyses of effects on estuarine nursery quality. Mar Ecol Prog Ser 325, 255-266.

Sturdivant, S.K., Brush, M.J., Diaz, R.J., 2013. Modeling the effect of hypoxia on macrobenthos production in the lower Rappahannock river, Chesapeake Bay, USA. PLoS ONE 8, e84140. https://doi.org/10.1371/journal.pone.0084140

Sussarellu, R., Suquet, M., Thomas, Y., Lambert, C., Fabioux, C., Pernet, M.E.J., Le Goïc, N., Quillien, V., Mingant, C., Epelboin, Y., Corporeau, C., Guyomarch, J., Robbens, J., Paul-Pont, I., Soudant, P., Huvet, A., 2016. Oyster reproduction is affected by exposure to polystyrene microplastics. Proc. Nat. Acad. Sci. 113, 2430-2435. https://doi.org/10.1073/pnas.1519019113

Thomas, P., Rahman, M.S., Kummer, J.A., Lawson, S., 2006. Reproductive endocrine dysfunction in Atlantic croaker exposed to hypoxia. Mar. Env. Res. 62, Supplement 1, S249-S252. https://doi.org/10.1016/j.marenvres.2006.04.031

Valverde, J.C., Aguado-Giménez, F., Hernández, M.D., García, B.G., 2012. Oxygen Consumption Response to Gradual Hypoxia in Spider Crab, Maja brachydactyla: Critical and Lethal Oxygen Saturations and Recovery Ability. J. WAS 43, 433-441. https://doi.org/10.1111/j.1749-7345.2012.00564.x

van der Meer, J., 2006. An introduction to Dynamic Energy Budget (DEB) models with special emphasis on parameter estimation. Journal of Sea Research 56, 85-102.

Vanderplancke, G., Claireaux, G., Quazuguel, P., Madec, L., Ferraresso, S., Sévère, A., Zambonino-Infante, J.-L., Mazurais, D., 2015. Hypoxic episode during the larval period has long-term effects on European sea bass juveniles (Dicentrarchus labrax). Mar. Biol. 162, 367-376. https://doi.org/10.1007/s00227-014-2601-9

Vaquer-Sunyer, R., Duarte, C.M., 2011. Temperature effects on oxygen thresholds for hypoxia in marine benthic organisms. Global Change Biology 17, 1788-1797. https://doi.org/10.1111/j.1365-2486.2010.02343.x

Vaquer-Sunyer, R., Duarte, C.M., 2010. Sulfide exposure accelerates hypoxia-driven mortalit. Limnol. Oceanogr. 55, 1075-1082. https://doi.org/10.4319/lo.2010.55.3.1075

Vaquer-Sunyer, R., Duarte, C.M., 2008. Thresholds of hypoxia for marine biodiversity. Proceedings of the National Academy of Sciences 105, 15452-15457. https://doi.org/10.1073/pnas.0803833105

Verberk, W.C.E.P., Bilton, D.T., 2011. Can Oxygen Set Thermal Limits in an Insect and Drive Gigantism? PLoS ONE 6, e22610. https://doi.org/10.1371/journal.pone.0022610

Verberk, W.C.E.P., Bilton, D.T., Calosi, P., Spicer, J.I., 2011. Oxygen supply in aquatic ectotherms: Partial pressure and solubility together explain biodiversity and size patterns. Ecology 92, 1565-1572. https://doi.org/10.1890/10-2369.1 
Verberk, W.C.E.P., Durance, I., Vaughan, I.P., Ormerod, S.J., 2016. Field and laboratory studies reveal interacting effects of stream oxygenation and warming on aquatic ectotherms. Glob. Change Biol. 22, 1769-1778. https://doi.org/10.1111/gcb.13240

Wang, W.X., Widdows, J., 1991. Physiological responses of mussel larvae Mytilus edulis to environmental hypoxia and anoxia. Mar Ecol Prog Ser 70, 223-236.

Wang, Y., Hu, M., Wong, W.H., Shin, P.K.S., Cheung, S.G., 2011. The combined effects of oxygen availability and salinity on physiological responses and scope for growth in the green-lipped mussel Perna viridis. Mar. pol. bul. 63, 255-261. https://doi.org/10.1016/j.marpolbul.2011.02.004

Wei, L., Zhang, X., Huang, G., Li, J., 2009. Effects of Limited Dissolved Oxygen Supply on the Growth and Energy Allocation of Juvenile Chinese Shrimp, Fenneropenaeus chinensis. J. WAS 40, 483-492. https://doi.org/10.1111/j.1749-7345.2009.00269.x

Widdows, J., Bayne, B.., Livingstone, D.., Newell, R.I.., Donkin, P., 1979. Physiological and biochemical responses of bivalve molluscs to exposure to air. Comparative Biochemistry and Physiology Part A: Physiology 62, 301-308. https://doi.org/10.1016/0300-9629(79)90060-4

Widdows, J., Newell, R.I.E., Mann, R., 1989. Effects of Hypoxia and Anoxia on Survival, Energy Metabolism, and Feeding of Oyster Larvae (Crassostrea virginica, Gmelin). The Biological Bulletin 177, 154-166.

Wu, R.S.S., 2002a. Hypoxia: from molecular responses to ecosystem responses. Mar. Pol. Bul. 45, 35-45. https://doi.org/10.1016/S0025-326X(02)00061-9

Wu, R.S.S., 2002b. Hypoxia: from molecular responses to ecosystem responses. Marine Pollution Bulletin 45, 35-45. https://doi.org/10.1016/S0025-326X(02)00061-9

Wu, R.S.S., Zhou, B.S., Randall, D.J., Woo, N.Y.S., Lam, P.K.S., 2003. Aquatic Hypoxia Is an Endocrine Disruptor and Impairs Fish Reproduction. Environ. Sci. Technol. 37, 1137-1141. https://doi.org/10.1021/es0258327

Zambonino-Infante, J.L., Claireaux, G., Ernande, B., Jolivet, A., Quazuguel, P., Sévère, A., Huelvan, C., Mazurais, D., 2013. Hypoxia tolerance of common sole juveniles depends on dietary regime and temperature at the larval stage: evidence for environmental conditioning. Proc. R. Soc. Lond. B Biol. Sci. 280. https://doi.org/10.1098/rspb.2012.3022

Zhang, J., Gilbert, D., Gooday, A.J., Levin, L., Naqvi, S.W.A., Middelburg, J.J., Scranton, M., Ekau, W., Peña, A., Dewitte, B., Oguz, T., Monteiro, P.M.S., Urban, E., Rabalais, N.N., Ittekkot, V., Kemp, W.M., Ulloa, O., Elmgren, R., Escobar-Briones, E., Van der Plas, A.K., 2010. Natural and human-induced hypoxia and consequences for coastal areas: synthesis and future development. Biogeosciences 7, 1443-1467. https://doi.org/10.5194/bg-7-1443-2010

Zhang, W., Cao, Z.-D., Peng, J.-L., Chen, B.-J., Fu, S.-J., 2010. The effects of dissolved oxygen level on the metabolic interaction between digestion and locomotion in juvenile southern catfish (Silurus meridionalis Chen). Comp. Biochem. Physiol. A Mol. Integr. Physiol. 157, 212-219. https://doi.org/10.1016/j.cbpa.2010.06.184

Zhou, B.S., Wu, R.S.S., Randall, D.J., Lam, P.K.S., 2001. Bioenergetics and RNA/DNA ratios in the common carp (Cyprinus carpio) under hypoxia. J. Comp. Physiol. B 171, 49-57. https://doi.org/10.1007/s003600000149

Zimmer, E.I., Ducrot, V., Jager, T., Koene, J., Lagadic, L., Kooijman, S.A.L.M., 2014. Metabolic acceleration in the pond snail Lymnaea stagnalis? J. Sea Res. 94, 8491. https://doi.org/10.1016/j.seares.2014.07.006 
